\title{
تقويم جودة الخدمة المكتبية من وجهة نظر مستعمليها
}

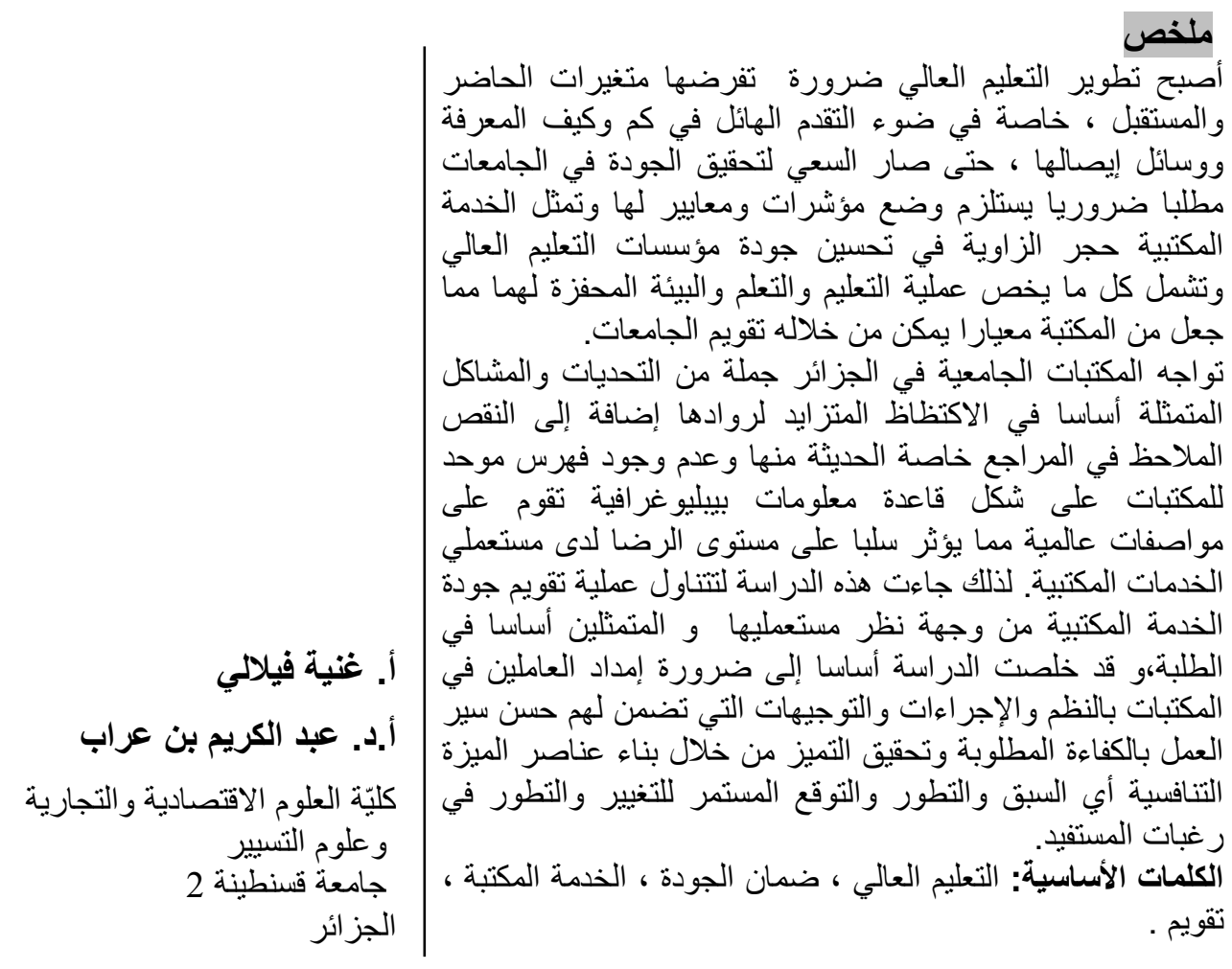

\section{Abstract}

أصبّح تطوير التعليم العالي ضرورة تفرضها

The industrial clusters are one of The development of higher

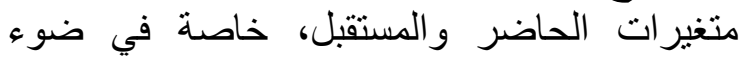
التقدم الهائل في كم وكيف المعرفة ووسائل إيصالها، education has become a necessity imposed by present and future variables, this is especially in light حتى صار السعي لتحقيق الجودة في الجامعات مطلبا ضروريا يستلزم وضع مؤشر ات ومعايير لها. of the tremendous progress in the quantity and quality of knowledge and their means of delivery, until the pursuit of quality in universities 
يمثل مدخل ضمان الجودة في التعليم العالي has become a necessary requirement which needs establishing its indicators and و standards . The library service is

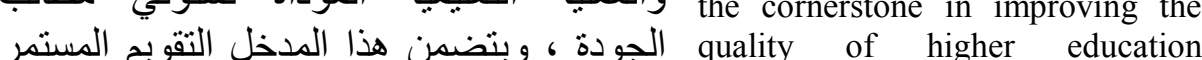
institutions, it contains everything related to teaching and learning

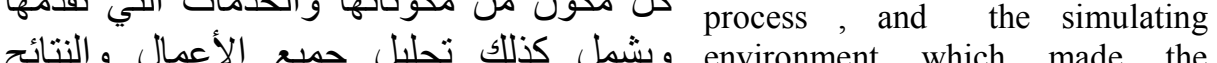
library a standard to evaluate

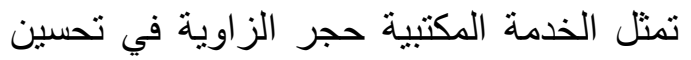

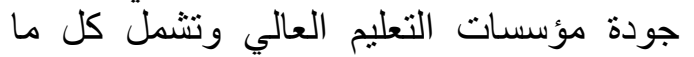

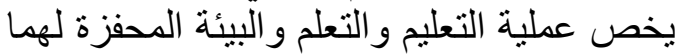

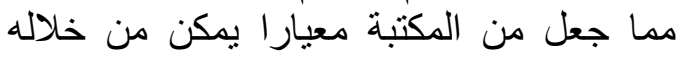
تقويم الجامعات. لذللك كان لابد أن تنتاول الناب عملية تقويم جودة

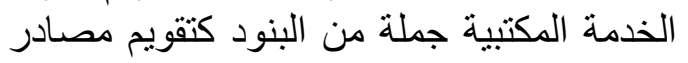

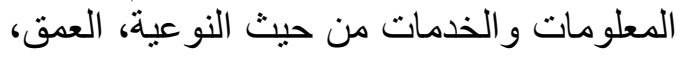

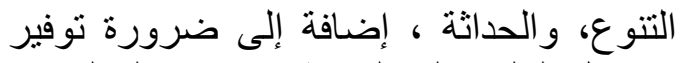

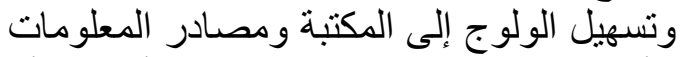

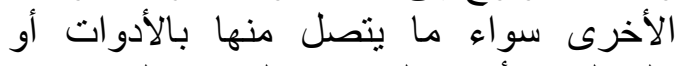

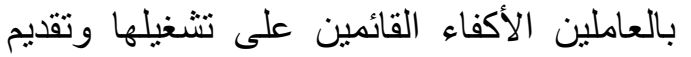
الخدمات فيها، وذللك تبعا للتطورات التين التهات الرقمية

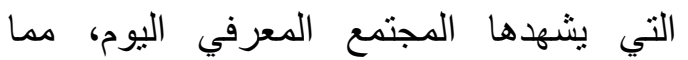

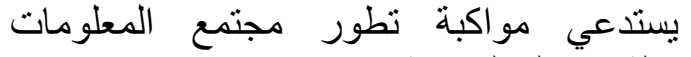

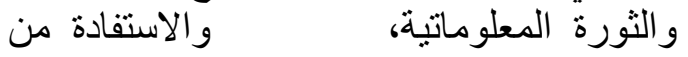
تكنولوجيا المعلومات في تطوير البحث البحت العلمي.

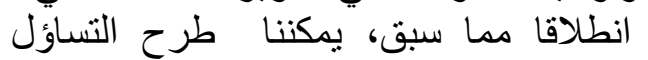

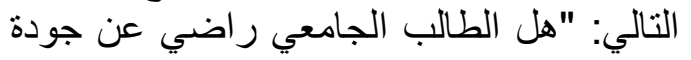

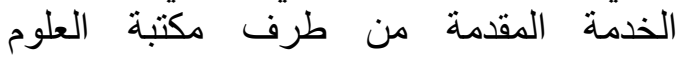
الاقتصادية التجارية وعلوم علوم التسيير لجامعة عبد universities.

Algerian university libraries are facing a set of challenges and problems mainly represented in the increasing overcrowded of its goers, the significant decrease in references particularly the recent ones, and the lack of unified index for libraries in form of bibliographic database based on international standards, which negatively affects the level of satisfaction among users of these library services. So this study is dealing with library service assessment from students viewpoint. The study has concluded that it is very important to supply workers in libraries with systems, procedures and guidelines to ensure the proper functioning efficiently and achieving excellence by building competitive advantage elements, which means the precession and continuous development of change and development in beneficiary's wishes.

Keywords: Higher education, quality assurance, library service, assessment.

فرضيات الدراسة: تستند الدراسة التطبيقية أساسا إلى فرضيتين هما : 


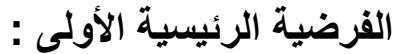

لا يوجد الاهتمام والتهيئة اللازمة للمكتبة من وجهة نظر طلبة كلية العلوم

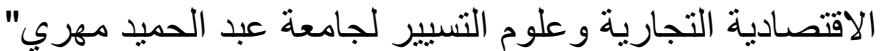
أ- ل لا يوجد اهتمام بالخدمات الإدارية للمكتبة من وجهة نظر طلبة لإية كلية العلوم

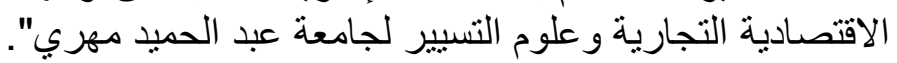

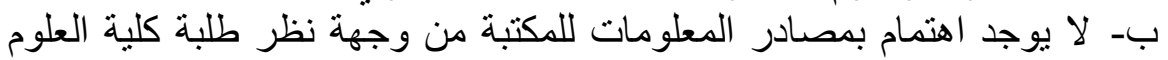

الإقتصادية التجارية وعلوم التسيير لجامعة عبد الحميد مهري".

ج- لا يوجد اهتمام بالجو العام للمكتبة من وجهة نظر طلبة كلية العلوم

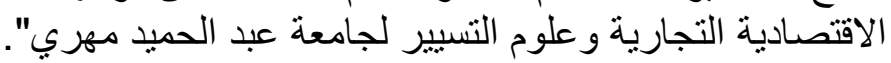

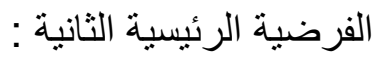

توجد فروق ذات دلالة إحصائية للخدمات الإدارية ومصادر المعلومات والجو العام للمكتبة باختلاف سنو ات الدات دالة الدرة

أـ ـ توجد فروق ذات دلالة إحصائية لتأثنير الخدمات الإدارية باختلاف سنوات

ب- توجد فروق ذات دلالة إحصائية لتأثثر مصادر المعلومات باختلاف سنوات

ج- توجد فروق ذات دلالة إحصائية لتأثثر الجو العام للمكتبة، فيما يتعلق بسنوات

\section{أولا :الإطسـار النظري للـدراسة النة}

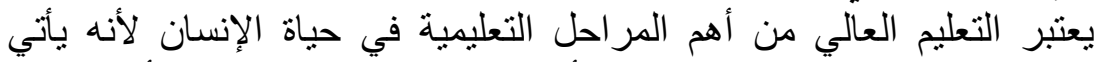

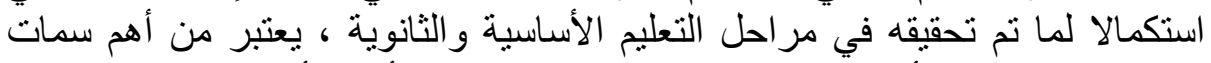

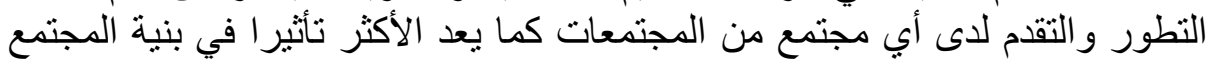

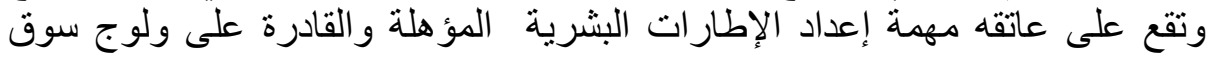

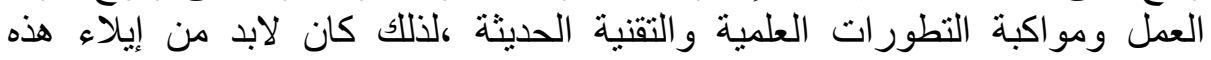

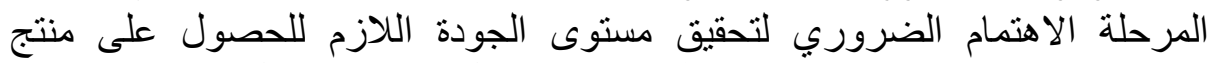
تعليمي فادر على تلبية متطلبات الطالب، سوق العمل، المجتمع وكل الجهات الداخلية

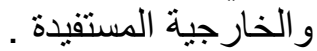

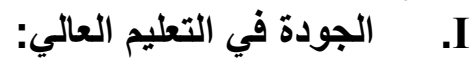

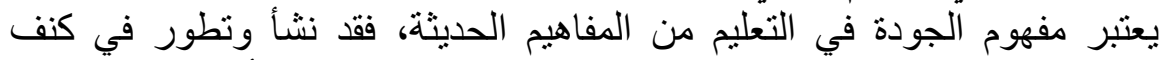

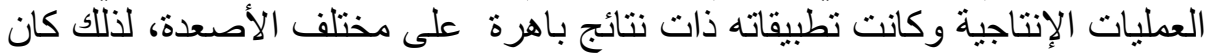

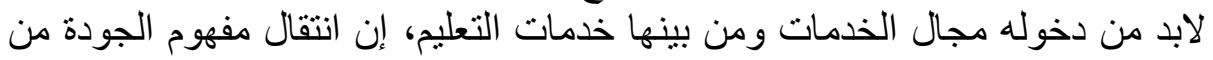
القطاع الصناعي إلى التعليم، و الجدل الذي تلا ذلك بين المختصين و الباحثين جعل منه التهان 


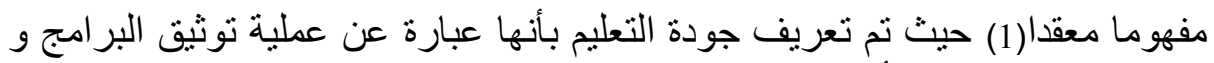

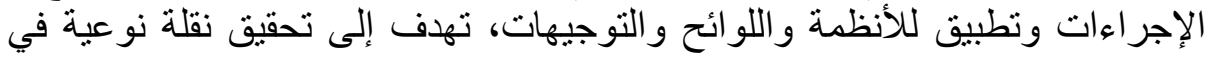

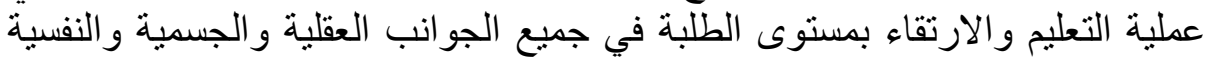

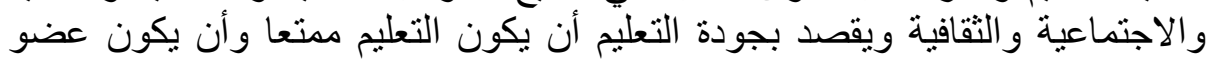

هيئة التدريس يقضاع وباستمر ار لجذب التب انتباه الطالب إلى المناقنتة (2) .

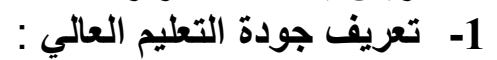

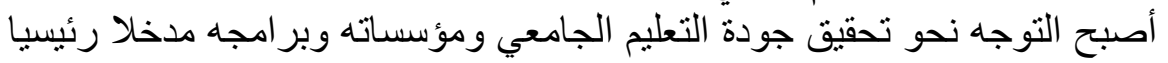

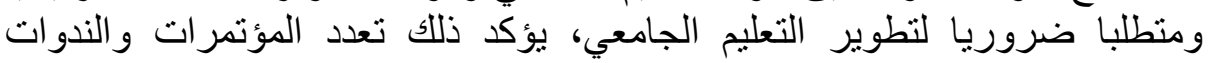

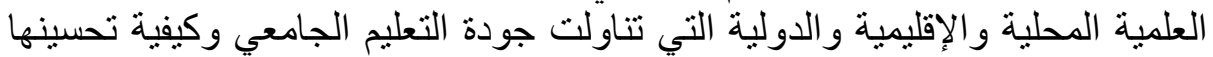
وتحقيقها وضمانها لمؤسساته وبر الامجها.

\section{1-1 تعريف الـ UNESCO}

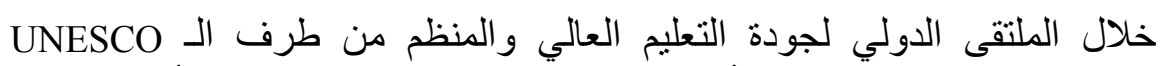

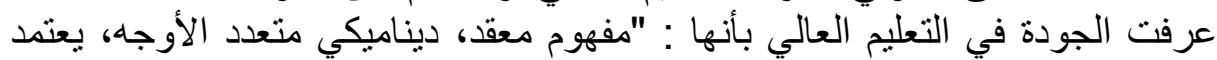

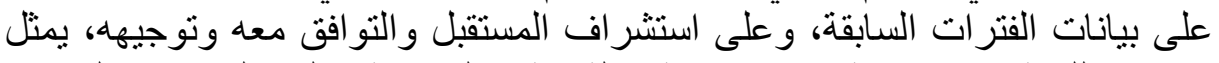
انعكاسا للبنية الاجتماعية، الاقتصادية، التقافية التية والسياسية على التى المستوى الجهوي

الوطني و الإقليمي ". (3) الإنهاعة (3)

\section{1 -2 تعريف وكالة ضمان الجودة البريطانية :}

عرفت وكالة ضمان جودة التعليم العالي البريطانية (QAA)، جودة التعليم العالي

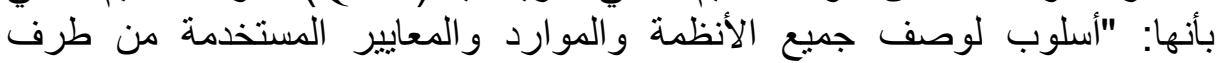

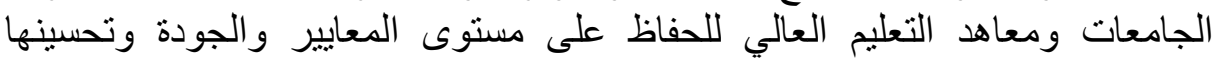

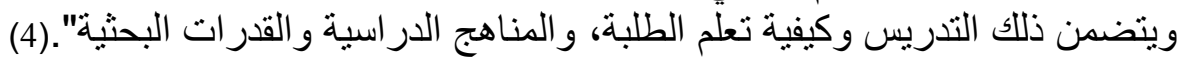

\section{3-1 تعريف الجمعية الأوروبية لضمان الجودة :ENQA}

توصي الجمعية الأوروبية لضمان الجودة في التعليم العالي بعدم اعتماد تعريف

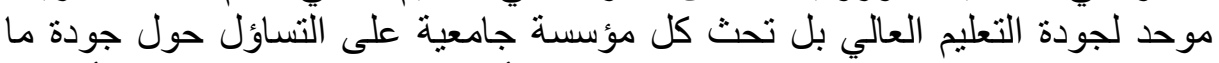

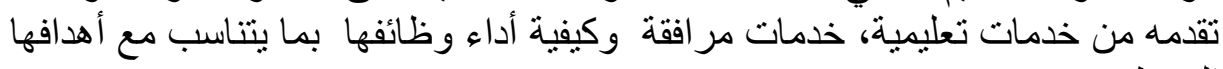

المسطرة (5).

\section{Corner 4-1 تعريف}

أشتار Corner إلى أنه عادة ما يتم تعريف الجودة في التعليم العالي اعتمادا على

أربعة أبعاد أساسية (6): النها

- البيئة الجامعية و البنية التحتية؛ 


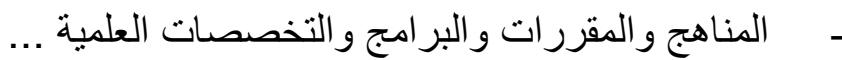

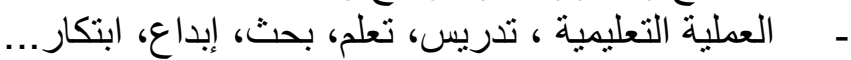

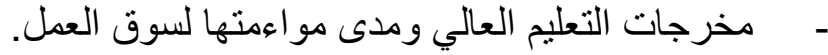

$$
\text { وينت ذلك وفق اعتبارين هما: }
$$

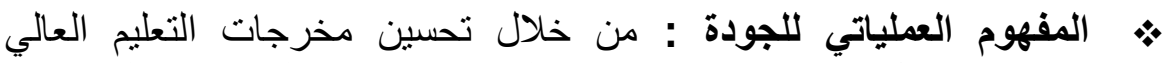

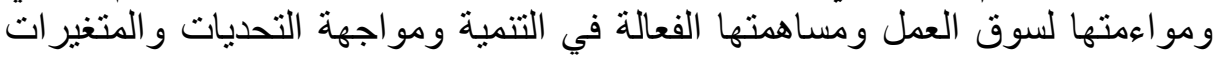

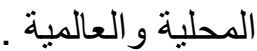

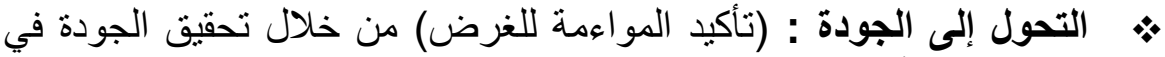

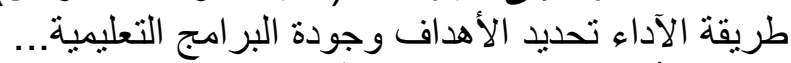
2- أهداف تطبيق الجودة في التعليم العالي:

لتطبيق مفاهيم الجودة في التعليم العالي جملة من الأليم الأهداف نذكر منها (7): تطوير النظام الإداري في الجامعة نتيجة وضوح العالئ الأدوار وتحديد المسؤوليات

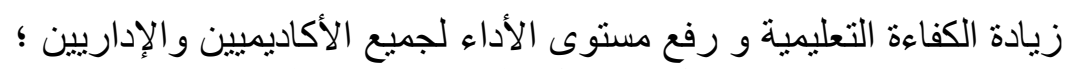

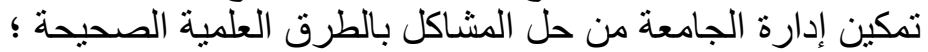

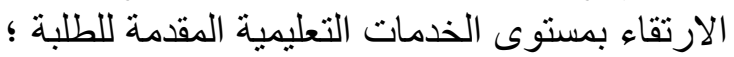
الوفاء بمتطلبات الطلبة، أعضاء هيئة التدريس، البحث التفية العلمي و المجتمع.

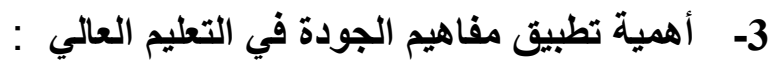

تظهر أهمية الجودة في خدمات التعليم العالي لتطوير البلدان والمجتمعات، لأن النيان

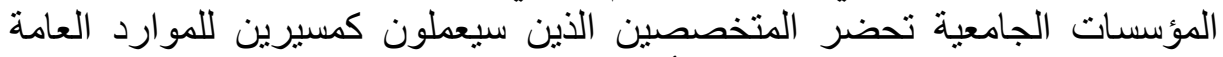

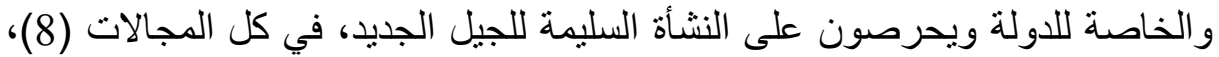

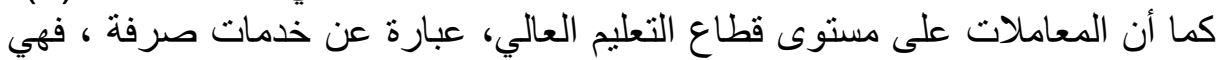

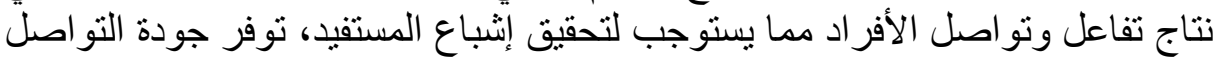

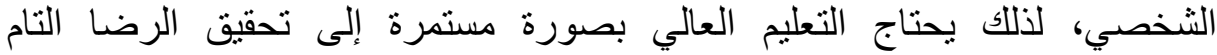

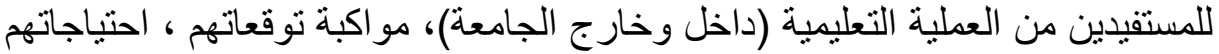
و اهتماماتهم (9) . يمكن توضيح ذلك من خلائل الثكل (دخل الثل التالي (10).

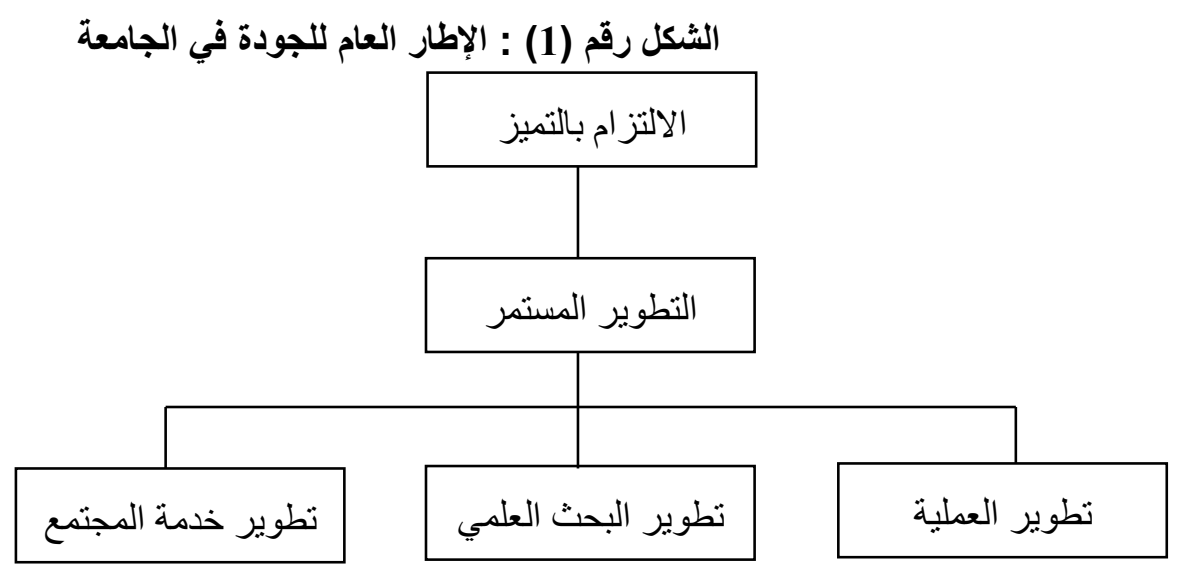


المصدر: القيسي هناء محمود، فلسفة إدارة الجودة في التربية والتعليم العالي الأساليب

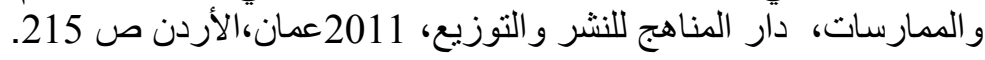

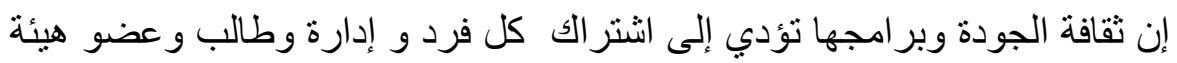

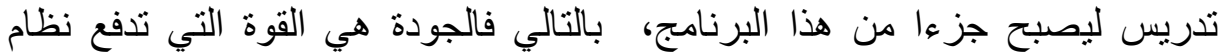
التعليم العالي بشكل فعال ليحقق أهدافه المسطرة المبن. 4- النموذج المفاهيمي للجودة في التعليم العالي: بالاعتماد على أدبيات جودة التعليم العالي تم تطوير نموذج مفاهيمي (11) ، يتكون

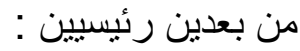

$$
\text { البعد الثاني: نوعية الأول: نوعية البراة الج التعليمية ؛ }
$$

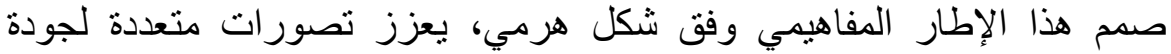

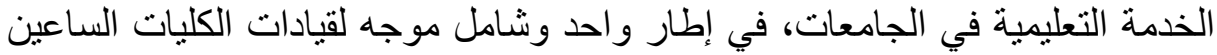

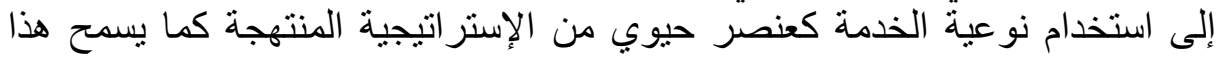

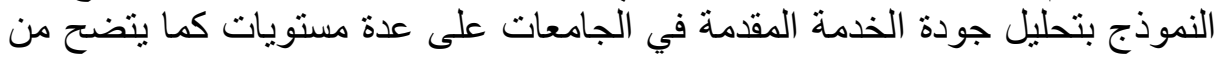

الشكل رقم (2) : النموذج المفاهيمي لجودة خدمة التعليم العالي

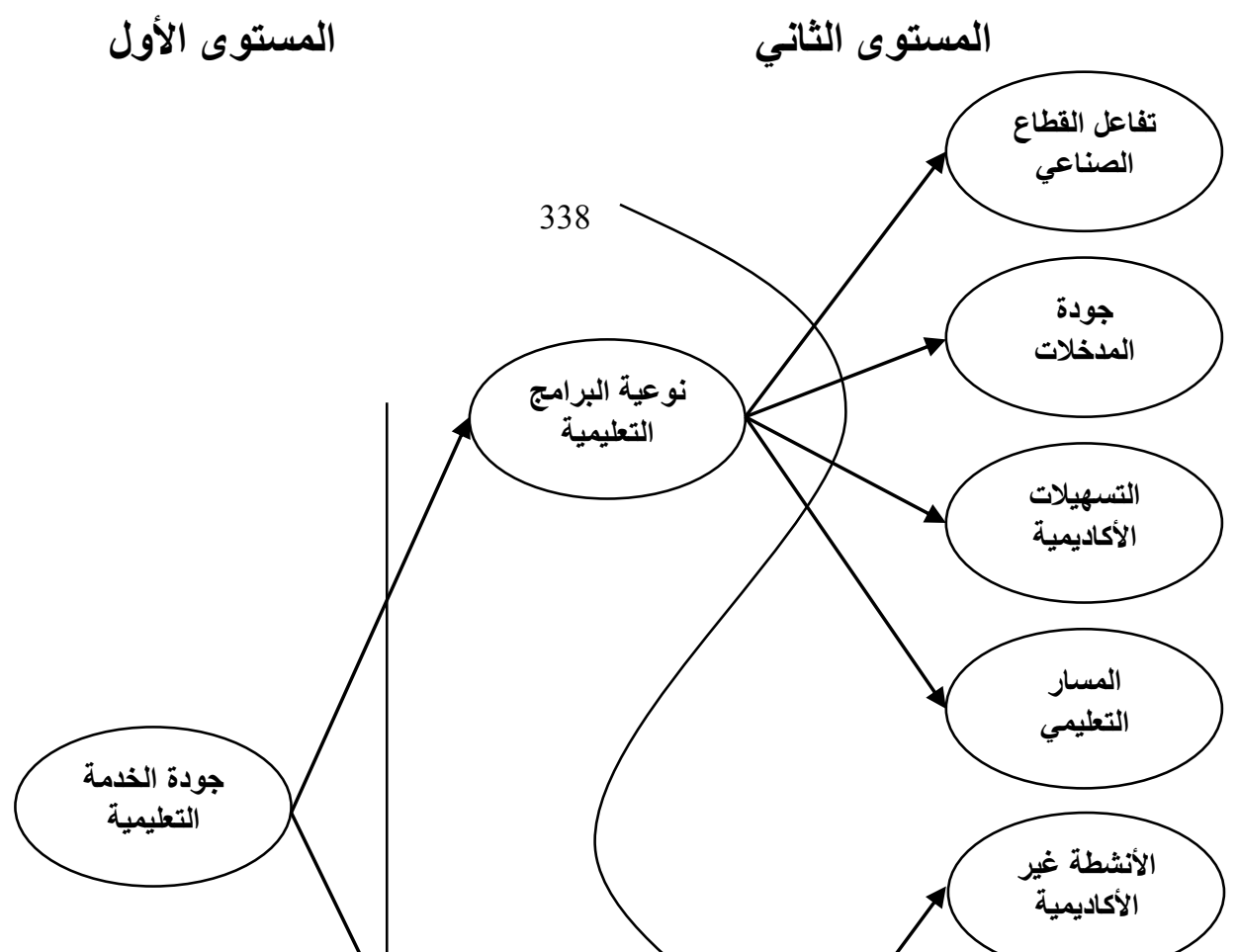


Source: Rajani Jain and all, conceptualizing service quality in higher education Asian Journal on quality , 2011, vol 12 iss 3 pp 296, 314.

أ- المستوى الأول: يضم بعدين نوعيين، هما نوعية البرامج التعليمية ونوعية

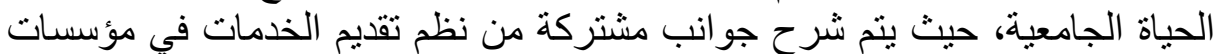

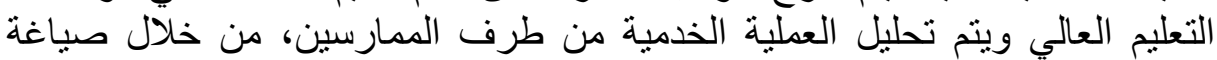

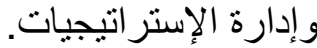


ب- المستوى الثاني: يضم ثمانية أبعاد فرعية ، تعكس جوانب محددة من عملية

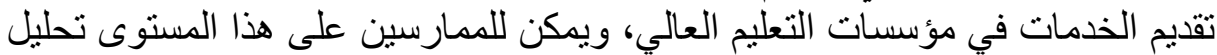
العملية الخدمية من خلال منابعة العمليات الإدارية اليومية العية العمارين

\section{1-4 نوعية البرامج التعليمية:}

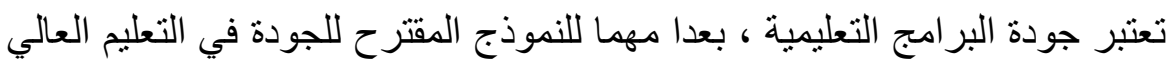

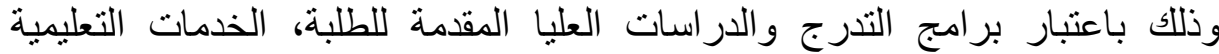

ويعرف بعد جودة البر امج التعليمية اعتمادا على أربعة أبعاد فرعية هي:

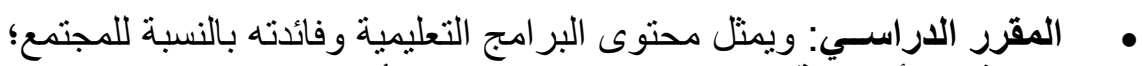

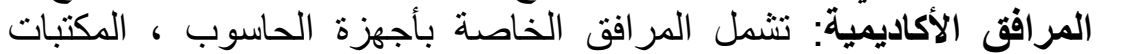

تفاعل قطاع الصناعة: تمثل العمليات الصناعية المقدمة للطلبة خلال مرحلة

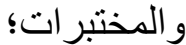

من برنامجهم التعليمي؛ جودة المدخلات: تمثل نوعية الطلبة وأعضاء هيئة التدريس في الجامعات

و المدخلات من الكفاءات المعرفية.

\section{2-4 نوعية الحياة الجامعية :}

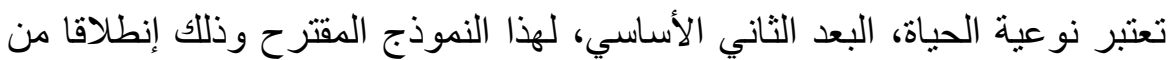

كون الطلبة ، يقضون جزءا كبير ا من حياتهم في الحرم الجامعي للكلية، بالتالي فالحياة التهات الاجتماعية للطلبة في الحرم الجامعي يصبح عاملاملا هاما في تحديد جودة الخدمة

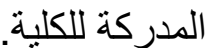

$$
\text { ويعرف بعد نوعية الحياة الجامعية اعتمادا على أربعة أبعاد فرعية هي: }
$$

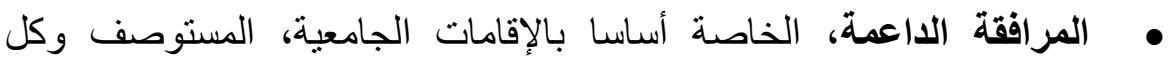

$$
\text { المرافق المتوفرة في الحرم الجامعي. }
$$

الأنشطة الطلابية غير الأكاديمية، كالأنشطة الاجتماعية .

$$
\text { المبنى الجامعي، موقعة وبيئته. }
$$

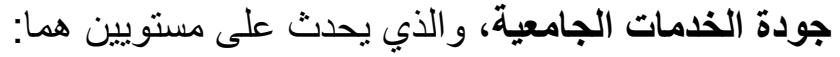

التفاعل بين مقدم الخدمة و المستفيد.

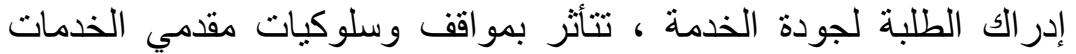

التعليمية وخبرتهم و التي تؤثر تأثثر ا مباشر ا على تقييم الطلبة لخدمات التعليم العالي. 


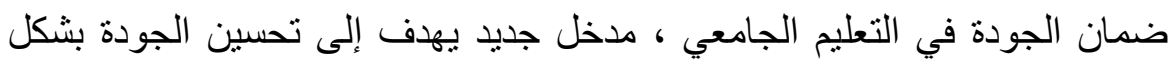

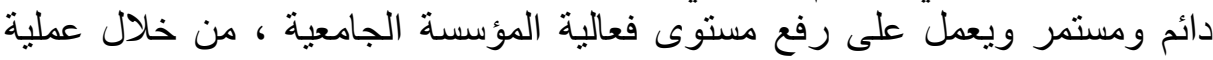
التقويم المؤسسي الثامل و المر اجعة المستمرة (12). ～. II

ضمان الجودة ، هي مجموع الأنشطة و الأساليب والإجراءات و التدابير التي تتخذ

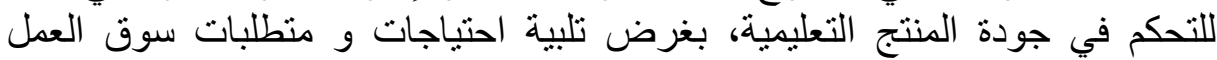

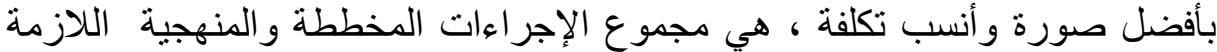

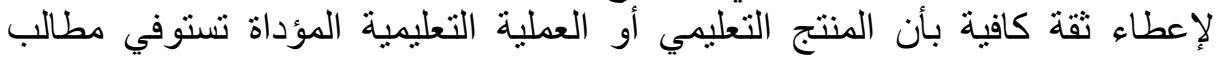

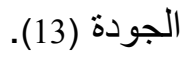

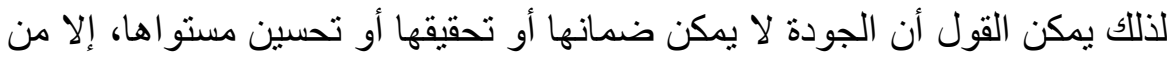

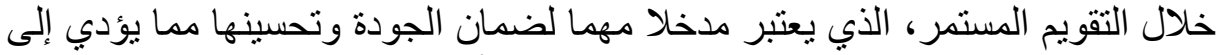
حصول المؤسسة على موثوقية كل من يتعامل معها أو يستفيد منها.

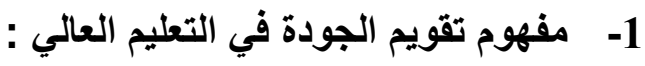

اعتلى التقويم بمختلف أنواعه ومستوياته مكانة مهمة في فضاء العمل التربوي و التعليمي في ظل تطور النظريات التربوية الحديثة وتوصلها إلى نتائج تؤكد دوره

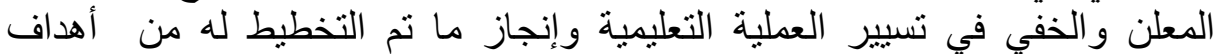

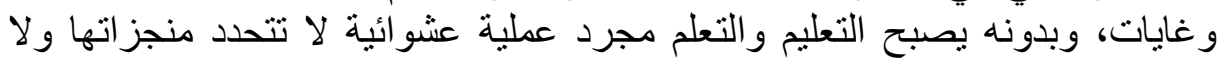
يعرف من خلالها جوانب قوتها ونواحي قصور ها (14) وتشتنمل عملية التقويم على التى

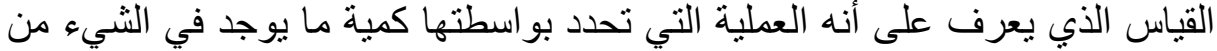

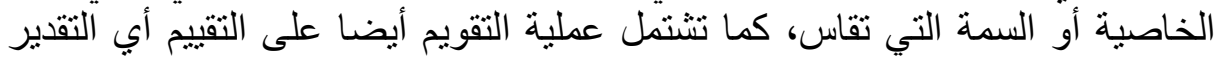

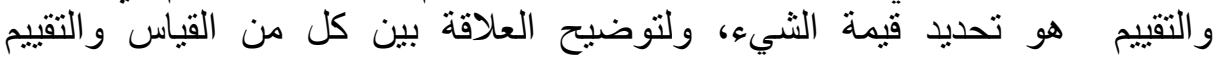
و والتقويم ندرج الثكل التالي:

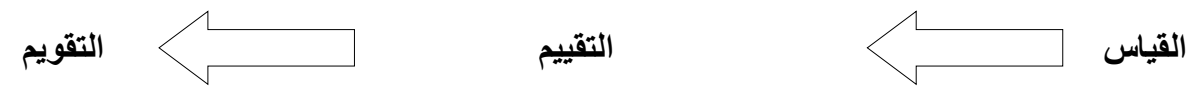

إعطاء قيمة رقمية للأشياء تقدير قيمة الأشياء علاج نقاط الضف وتعزيز نقاط القوة

المصدر : رافدة عمر الحريري ،القيادة وإدارة الجودة في التعليم العالي ، دار الثقافة للنشر و التوزيع، القاهرة ،2012 ص 325.

\section{2- مجالات التقويم في التعليم العالي :}

يعد التقويم مكونا مهما من مكونات النظام التعليمي لا يمكن إغفال أهميته و أثره،

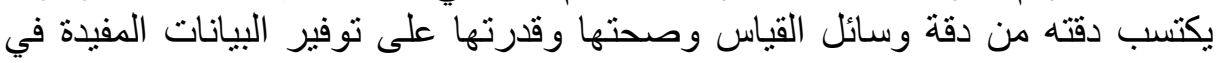




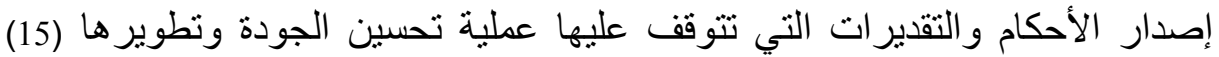

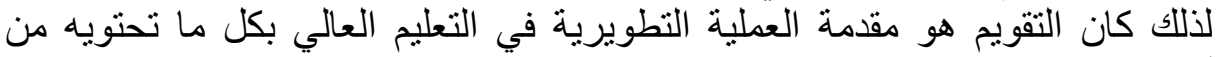

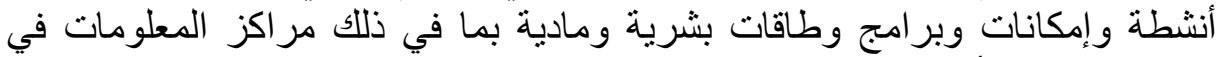

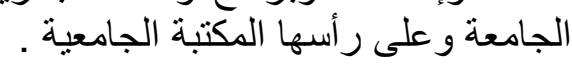

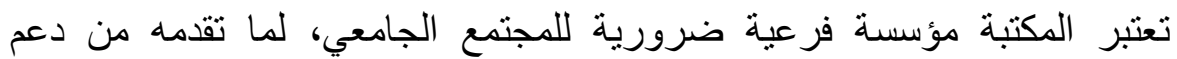

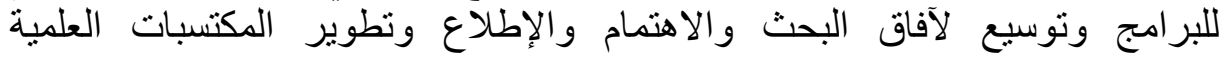

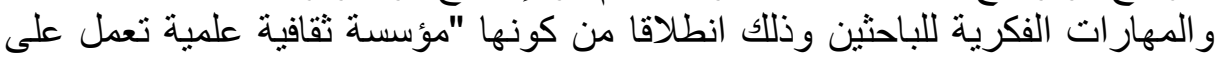

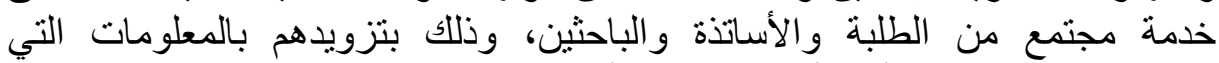

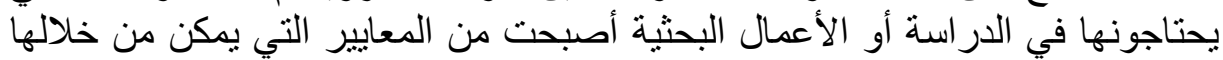

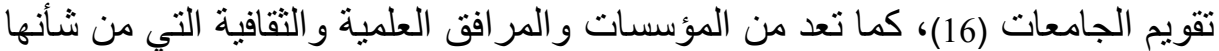

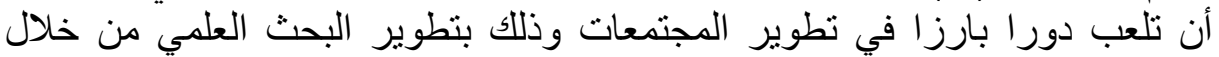
تقديم خدمات ذات فعالية للقائمين عليه.

\section{1-2 تعريف المكتبة الجامعية:}

the library in the في كتابه Inorman Higham المكتبة الجامعية ، كما عرفها university

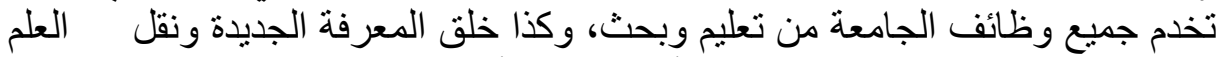

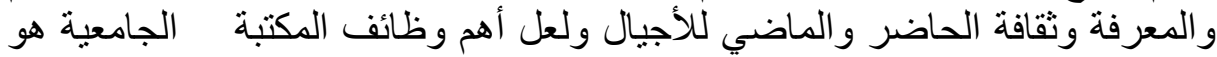

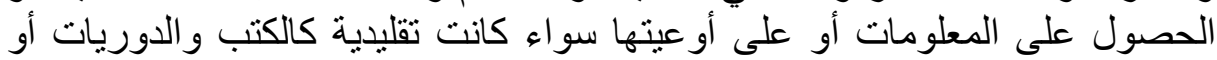

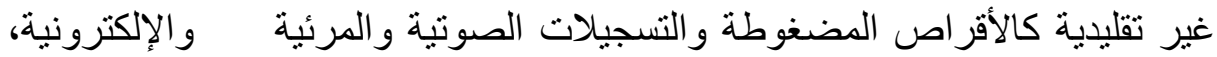
إضافة إلى الخدمة الإدارية وتسيير المكتبة من إمكانيات بشرية مؤهلة والة ومانية والادية كافية

\section{2-2 2 أهداف المكتبة الجامعية:}

تستمد المكتبة أهدافها من الجامعة ذاتها، و عليه فهي تساعد في نقل المعرفة وتلبية

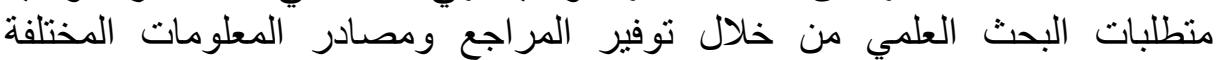

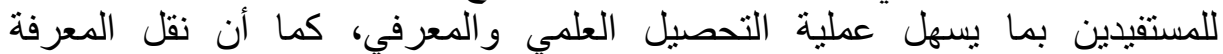
ونشرها من مكان إلى آخر ومن جيل إلى آخر تمكن الخريج الجامعي من تولي المعاي

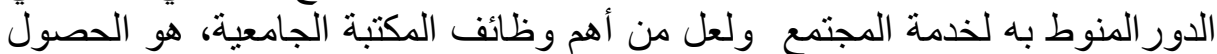

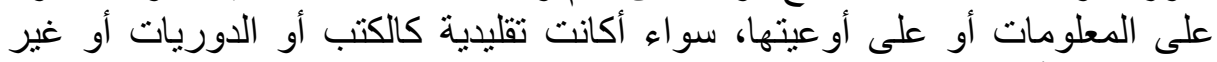

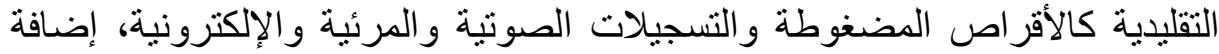

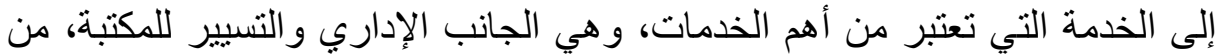
إمكانيات بشرية مؤ هلة ومادية كافية.

2 -3 وظائف المكتبة الجامعية: 
يمكن إدراج أهم الوظائف المنوطة بالمكتبة الجامعية فيما يلي (18): - - - توفير المقتنيات و المصادر الضرورية لمستعميلها من باحثين وطلبة . - إعداد قو ائم منظمة بمحتويات المكتبة وبأتنكال مختلفة ولكل الأوعية لتسهيل عملية الإعارة. - ماعت - - القيام بمعارض إع وندو ات قصد التعريف بمحتويات المكتبة . - توفير العنصر البشري المؤهل مكتبيا وتقنيا.

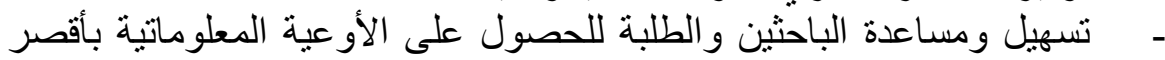

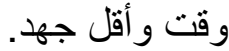
- - تأمين خدمة الإعارة و التبادل بين المكتبات . أما الأسباب التي دفعت المكتبات الجامعية إلى استخدام تكنولوجيا المعلومات فيمكن

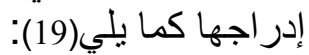

• تغير طبيعة المعلومات والحاجة إليها نتيجة التقدم العلمي والاجتماعي

تضاعف ونمو حجم الإنتاج الفكري سنويا بنسبة 10\% ؛ و الاقتصـادي؛

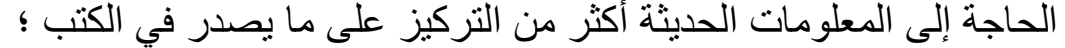

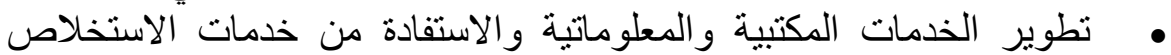

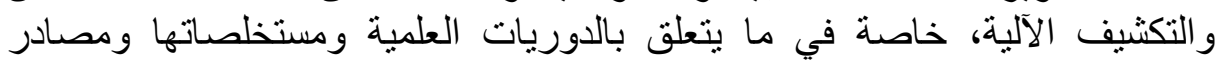
المعلومات غير التقليدية؛

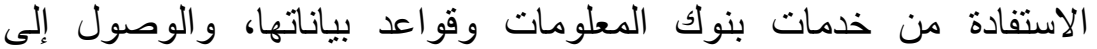

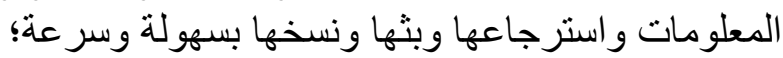
• المساهمة في إقامة شبكات ونظماتها ونية آلية معلوماتية تعاونية بين المكتبات

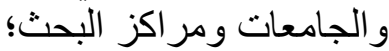
• إيجاد حل لمشكلة ضيق المكان، وهي مشكلة كل المكتبات مهما كانت

مساحتها؛ • تقديم خدمات أفضل بتكاليف أقل، من خلال الاستعاضة عن شراء أوعية المعلومات المرجعية التقليدية الغالية الثمن كالموسوعات والثاتية الدوريات والكثافات،

$$
\text { بأقر اص ليزر CD-ROM }
$$

\section{4-2 التحديات التي تواجه المكتبة الجامعية الجزائرية :}

تسعى المكتبات الجامعية إلى تحسين علاقاتها مع روادها، من خلال تطوير

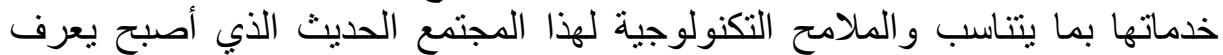
بعصر المعلوماتية ويرى الباحثون أنه بعد سنة 2012 ستكون جميع المعلومات النهات

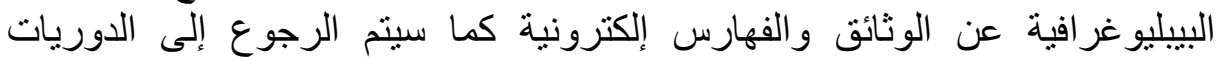
إلكترونيا بنسبة 90\% أما الكتب بالنصوص الكاملة فستكون إلكترونية بنسبة 20\% مما سيؤدي إلى التراجع عن إصدار المطبوعات الورقية، من ثم فإن المكتبة الجامعية 
الجزائرية تو اجه جملة من التحديات نلخصها فيما يلي:

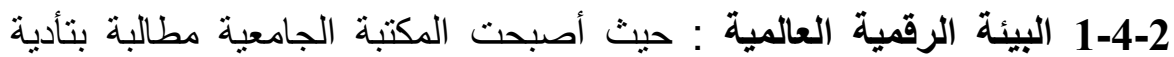

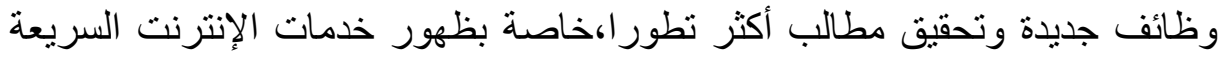

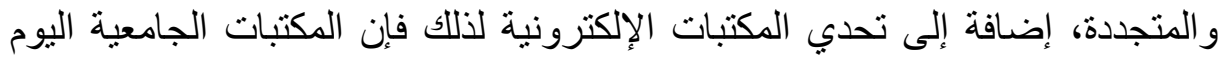

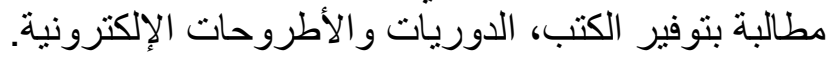

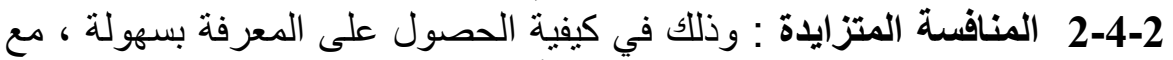

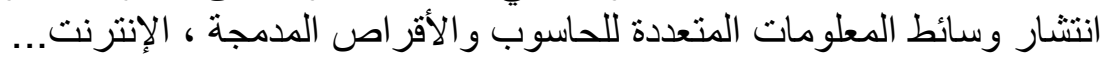

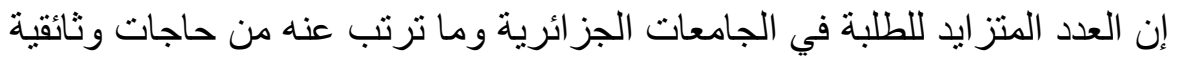

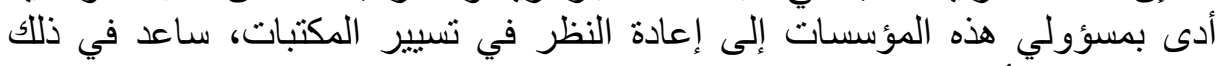

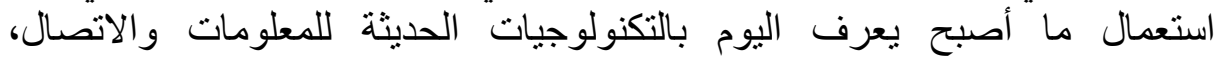

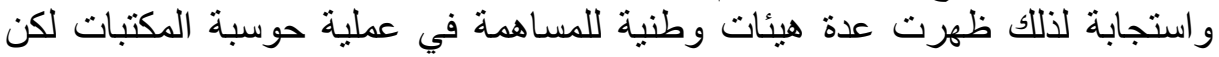

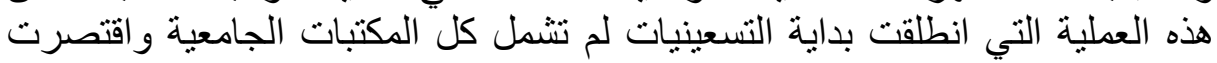

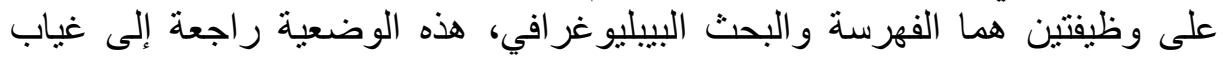

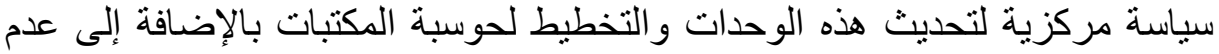
إعطاء كل الصلاحيات و الإمكانبات المادية لمسؤولي المكتبات حتى بساهموا بفعالية بلإلية في هذه العملية.

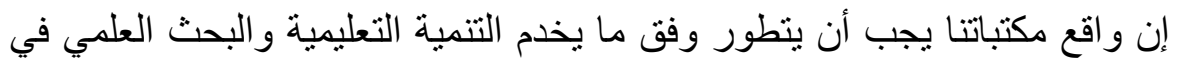

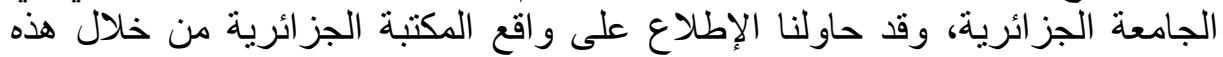

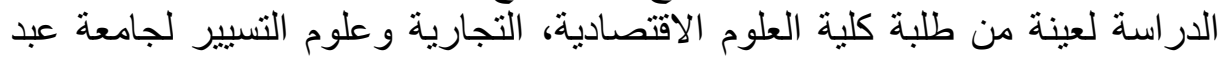
الحميد مهري باعتبار ها الفئة التي تستخدم المكتبة بشكل حتمي ودائم .

ثانيا : الدراسة التطبيقية

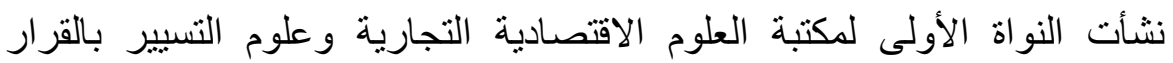

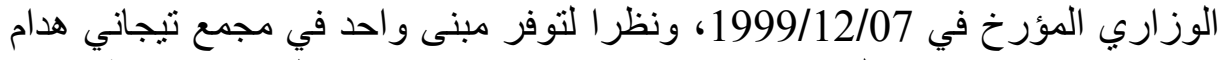

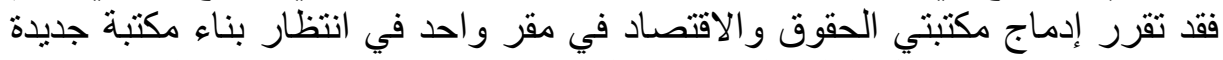
للكلية، تحقق ذلك بانتقال الكلية إلى مقر ها الجديد بالمدينة الجديدة علي منجلي.

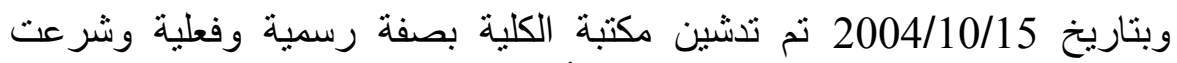

المكتبة في تقديم خدماتها اعتمادا على عدة أقسام هي بنك الإعارة، قاعة الإنة الإنترنت وقاعة الدطالعة الحرة (20).

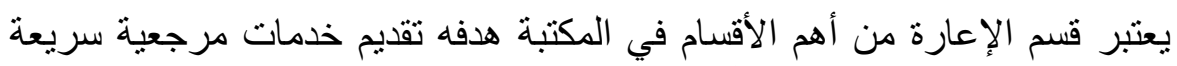

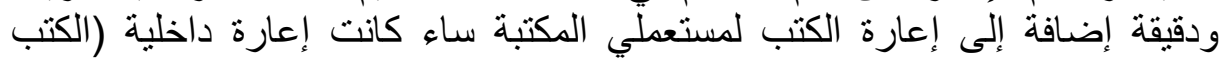
النادرة والمرجعية) أو إعارة خارجية والتي تتم بالرجوع إلى الفهارس الأوتوماتيكية 
والورقية المعدة لهذا الغرض .

I إجراعات الدراسة التطبيقية : I

1- مجتمع البحث وعينته: يتمثل مجتمع البحث من من طلبة كلية العلوم

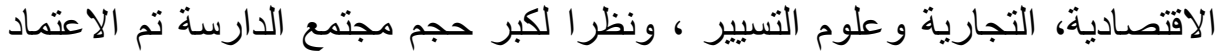

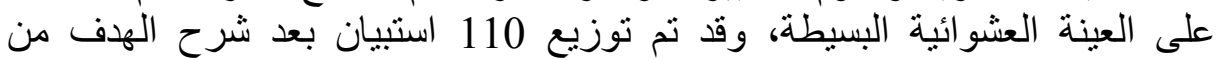

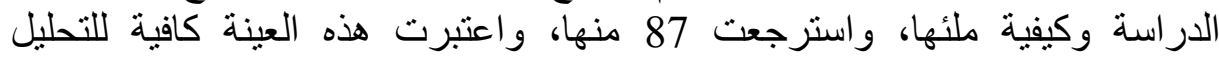

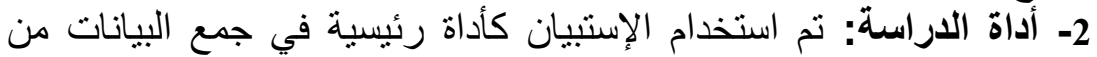

واعتماد النتائج .

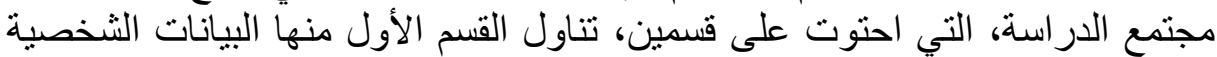

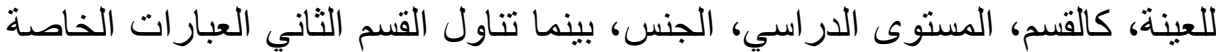

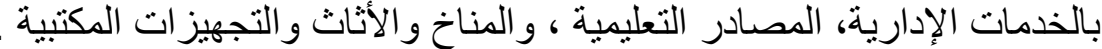

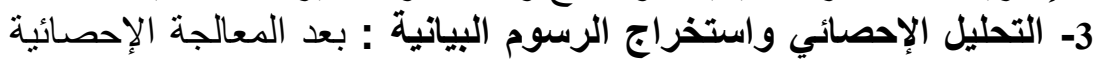

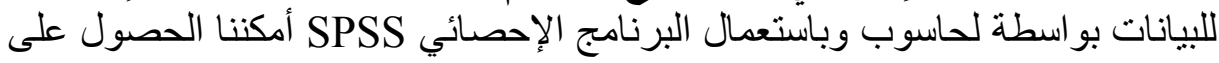

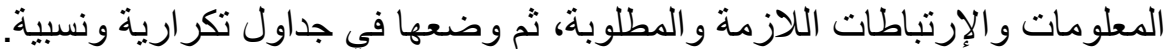

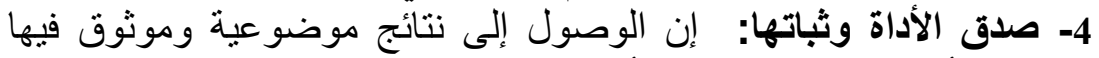

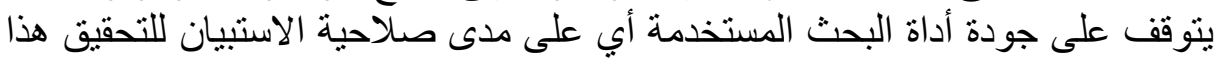

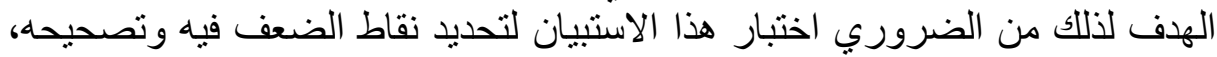

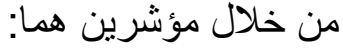

1-4 الصدق: لضمان صدق الأداة، قمنا بإجراء دراسة أولية على على عينة

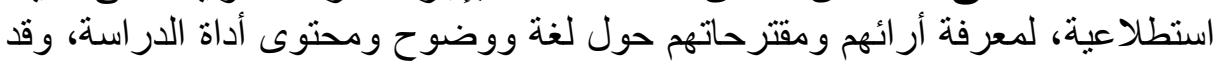

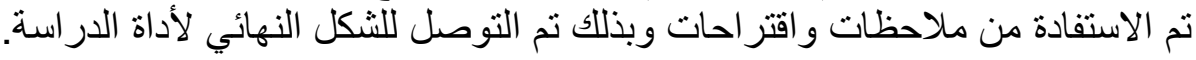
2-4 الثبات: نم التحقق من ثبات الأداة بفحص الاتساق الداخلي لفقرات الاستبيان

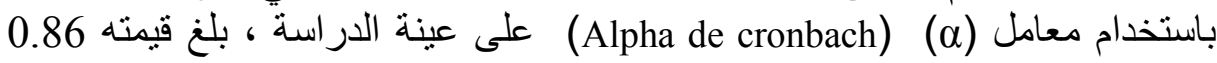

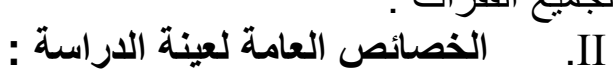
تتكون عينة الدراسة من 87 مفردة ، حيث بظهر الجدول رقم 1 المعلومات

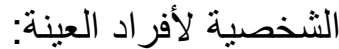

الجدول رقم (01) : معلومات شخصية عن أفراد العينة

\begin{tabular}{|c|c|c|c|}
\hline النسبة & التكرار & \multicolumn{2}{|c|}{ البيان } \\
\hline 35.6 & 31 & ذكر & \\
\hline 64.4 & 56 & أنثى & \\
\hline
\end{tabular}




\begin{tabular}{|c|c|c|c|}
\hline 28.7 & 25 & الأولى & \multirow{4}{*}{ سنة الدراسة } \\
\hline 20.7 & 18 & الثانية & \\
\hline 25.3 & 22 & الثالثة & \\
\hline 25.3 & 22 & ماستر & \\
\hline 29.9 & 26 & تجارة & \multirow{3}{*}{ الكلية } \\
\hline 36.8 & 32 & تسيير & \\
\hline 33.3 & 29 & اقتصاد & \\
\hline
\end{tabular}

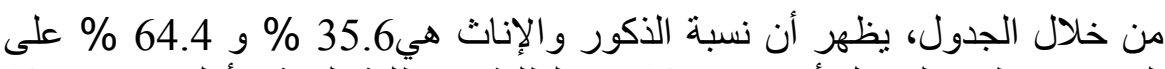

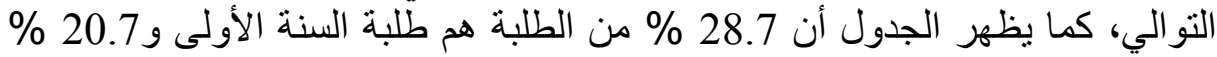
طلبة السنة الثانية و 25.3 \% طلاب السنة الثالثة و 25.3 \% طلة طلة الثة طلة الماستر (1 و2). وينقسم الطلبة محل الدراسة حسب القسم إلى: 29.9 \% من الطلبة يدرسون بقسم التجارة، و36.8 \% من الطلبة يدرسون بقسم التسيير و33.3 \% م منهم يدرسون بقسم

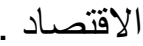

$$
\text { III }
$$

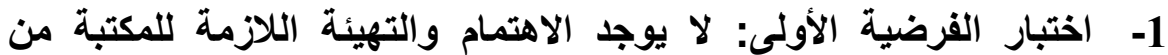

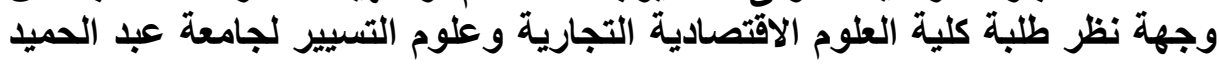

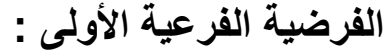

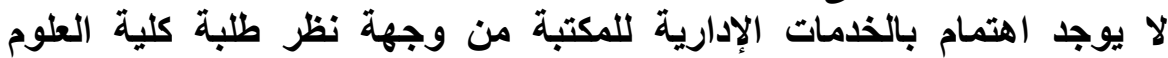

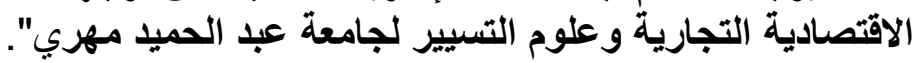

الجدول رقم (03): نتائج المتوسط الحسابي والانحراف المعياري واختبار t لعينة

\begin{tabular}{|c|c|c|c|c|}
\hline المعنوية & $\mathbf{T}$ & الانعراف & الحستوسطي & 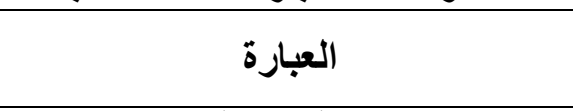 \\
\hline 0.000 & 22.90 & 1.13 & 2.77 & مواعيد فتح المكتبة ملائمة لروادها \\
\hline 0.000 & 24.81 & 1.11 & 2.97 & 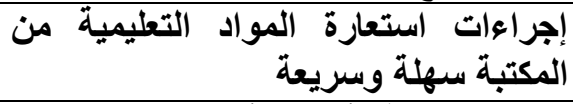 \\
\hline 0.000 & 26.04 & 1.04 & 2.91 & المداسبة المتاحة أمام الأعضاء للإستعارة \\
\hline 0.000 & 21.34 & 1.32 & 3.01 & موظفوا المكتبة متواجدون أثناء مواعيد \\
\hline
\end{tabular}

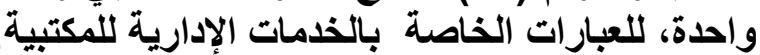




\begin{tabular}{|c|c|c|c|c|}
\hline & & & & فتح المكتبة \\
\hline 0.000 & 17.52 & 1.29 & 2.43 & ميدون لمقترحات المكتبة متعاونون ومستمعادون \\
\hline 0.000 & 19.15 & 1.21 & 2.48 & طتب منهم الموظفون بسرعة الرد وتوفير ما \\
\hline 0.000 & 21.92 & 1.14 & 2.69 & نظام الفهرس الإكتروني في المكتبة فعال \\
\hline 0.000 & 21.82 & 0.94 & 2.20 & ألمس تطور في خدمات المكتبة باستمرار \\
\hline
\end{tabular}

المصدر : من إعداد فريق البحث على ضوء نتائج الاستبيان.

نلاحظ من خلال الجدول، أن العبارة رقم 4 الخاصة بالخدمات وموظفي المكتبة متواجدون في المكتبة أثناء مو اعيدها جاءت في في المرتبة المارة الأولى بمتوسط حسابي قدره

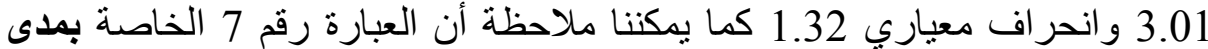
فعالية نظام الفهرس الإكتروني للمكتبة، بلغ متوسطها الحسابي 2.69 في نفس الوقت

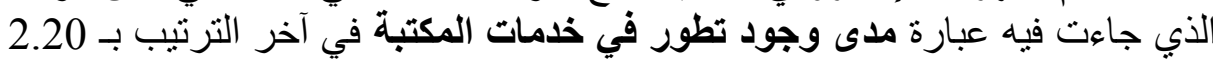

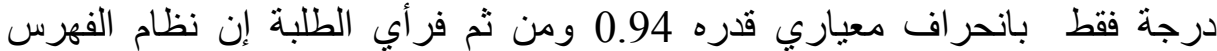

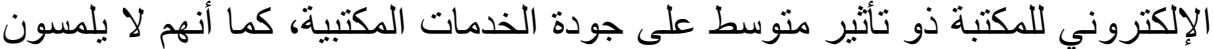

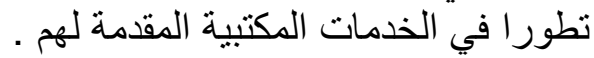

الفرضية الفرعية الثانية: الفية

لا يوجد إتمام بمصادر المعلومات للمكتبة من وجهة نظر طلبة كلية العلوم

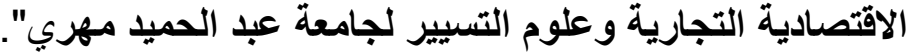

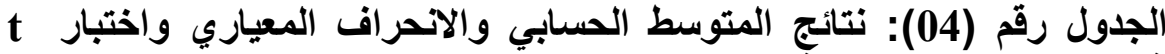
لعينة واحدة للعبارات الخاصة بمصادر المعلومات:

\begin{tabular}{|c|c|c|c|c|}
\hline المعنوية & $\mathbf{T}$ & المعياري & الحستابي & العبارة \\
\hline 0.000 & 23.57 & 1.02 & 2.57 & الحتياجاتي من الورقية متيث المرفرة \\
\hline $\mathbf{0 . 0 0 0}$ & 24.20 & 0.97 & 2.53 & والمتياجاتي الإكترونيةّ منوفرة المراجع \\
\hline 0.000 & 28.30 & 0.88 & 2.68 & المكتبة حديثة والمصادر المتوفرة في \\
\hline 0.000 & 21.26 & 1.21 & 2.76 & الكتب في والمواكنها الأخرى متواجدة \\
\hline 0.000 & 18.17 & 1.13 & 2.21 & هناك تنوع ، مكتبات إلكترونية المصادر كتب، \\
\hline
\end{tabular}

المصدر : من إعداد فريق البحث على ضوء نتائج الإستبيان 
نلاحظ من خلال الجدول (04) أن العبارة الرابعة الكتب والمواد الأخرى متواجدة

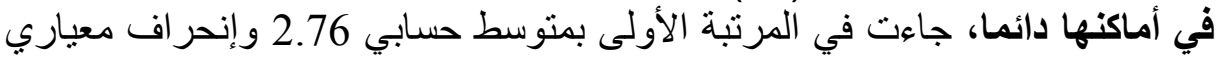

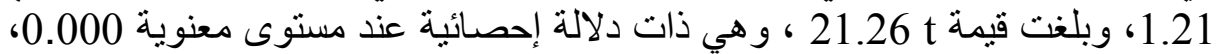

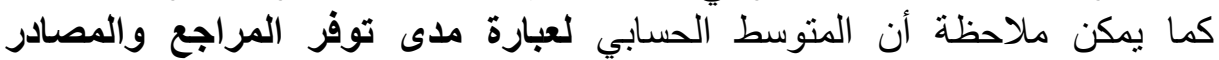

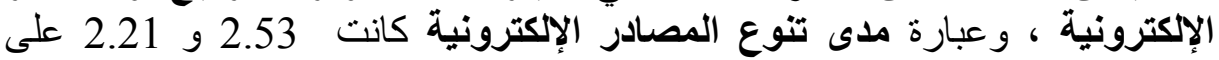
الترنيب و إنحر اف معياري يقدر بـ 0.97 و 1.13 على التئ الترتيب.

الفرضية الفرعية الثالثة:

لا يوجد إهتمام بالجو العام للمكتبة من وجهة نظر طلبة كلية العلوم الإقتصادية

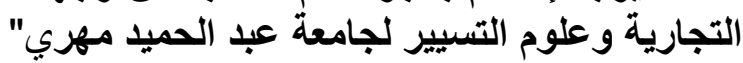

الجدول رقم (05): نتائج المتوسط الحسابي والاتحراف المعياري واختبار t لعينة واحدة للعبارات الخاصة بالجو العام للمكتبة.

\begin{tabular}{|c|c|c|c|c|}
\hline المعنوية & $\mathbf{t}$ & المعياري & الحسابي & العبارة \\
\hline 0.000 & 19.758 & 1.25 & 2.64 & جو المكتبة والهلوو مناسبين \\
\hline 0.000 & 28.422 & 1.13 & 3.44 & المكتبة نظيفة ومرتبة \\
\hline 0.000 & 23.741 & 1.13 & 2.87 & التهوية في المكتبة جيدة \\
\hline 0.000 & 31.160 & 1.07 & 3.59 & مقاعد ومناضد المكتبة مريحة \\
\hline
\end{tabular}

المصدر : من إعداد فريق البحث على ضوء نتائج الإستبيان

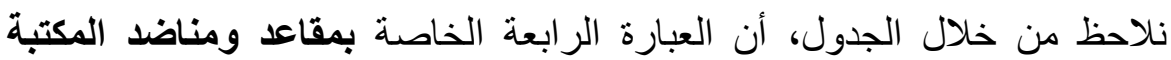

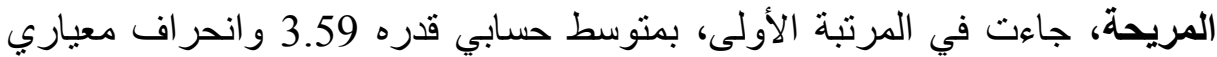

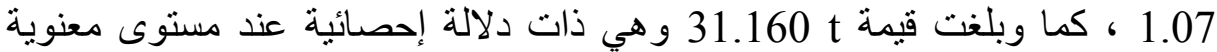

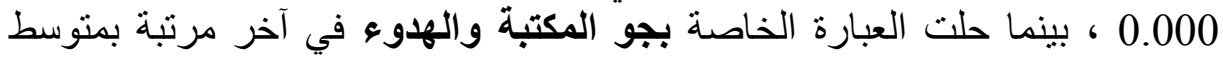

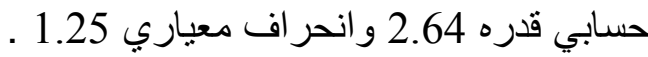

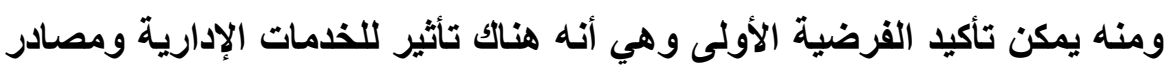

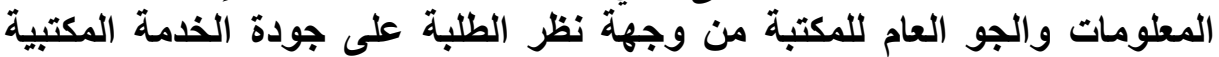
وذلك بمستويات مختلفة.

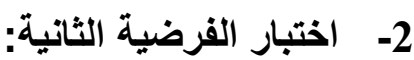

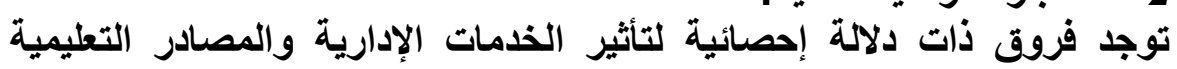

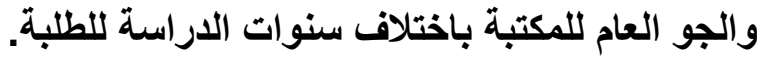


لفحص صحة الفرضية سنقوم باختبار تحليل التباين الأحادي Anova one way لمعرفة مدى التباين بين الطلبة حسب سنوات الدراسة في تقييمهم لجودة الخدمة المكتبية.

الفرضية الفرعية الأولى: توجد فروق ذات دلائة إحصائية لتأثير الخدمات الإدارية باختلاف سنوات الدراسة:

الجدول رقم (06): تحليل التباين للخدمات الإدارية حسب معيار سنوات الدراسة

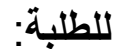

\begin{tabular}{|c|c|c|c|c|c|c|}
\hline الدلالة & $\mathbf{F}$ & المتوسطات & المربعوع & & البيان & \\
\hline \multirow{2}{*}{0.312} & \multirow{2}{*}{1.208} & 1.626 & 4.579 & المجموعات & \multirow{2}{*}{ ملائمةً للرواد المكتبة } & \\
\hline & & 1.263 & 104.824 & المجموعات & & \\
\hline \multirow{2}{*}{0.602} & \multirow{2}{*}{5.342} & 5.767 & 17.301 & المجموعات & \multirow{2}{*}{ 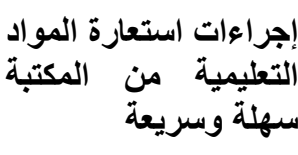 } & \\
\hline & & 1.079 & 89.593 & المجموعات & & \\
\hline \multirow{2}{*}{0.405} & \multirow{2}{*}{0.983} & 1.066 & 3.199 & المجموعات & \multirow{2}{*}{ مناسبة } & \\
\hline & & 1.085 & 90.066 & المجموعات & & \\
\hline \multirow{2}{*}{0.181} & \multirow{2}{*}{1.662} & 2.814 & 8.443 & المجموعات & \multirow{2}{*}{ متواجدون أثناء مواعيد } & الخدمات \\
\hline & & 1.607 & 140.545 & المجموعات & & الإدارية \\
\hline \multirow{2}{*}{0.114} & \multirow{2}{*}{2.044} & 3.285 & 9.856 & المجموعات & \multirow{2}{*}{ 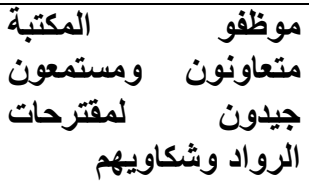 } & \\
\hline & & 1.607 & 133.409 & المجموعات & & \\
\hline \multirow{2}{*}{$\mathbf{0 . 0 3 7}$} & \multirow{2}{*}{2.949} & 4.037 & 12.111 & المجموعات & \multirow{2}{*}{ 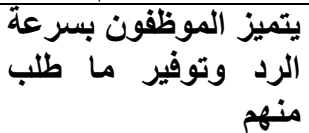 } & \\
\hline & & 1.869 & 113.618 & خارج & & \\
\hline
\end{tabular}




\begin{tabular}{|c|c|c|c|c|c|}
\hline & & & & المجمو عات & \\
\hline \multirow{2}{*}{0.605} & \multirow{2}{*}{0.618} & 0.821 & 2.463 & المجموعات & \multirow{2}{*}{ فظعال } \\
\hline & & 1.827 & 110.153 & المجموعات & \\
\hline \multirow{2}{*}{$\mathbf{0 . 0 2 0}$} & \multirow{2}{*}{3.446} & 2.794 & 8.382 & المجموعات & \multirow{2}{*}{ ألمكتبة باستمر في خدمات } \\
\hline & & 0.811 & 67.296 & المجموعات & \\
\hline
\end{tabular}

المصدر : من إعداد فريق البحث على ضوء نتائج الاستبيان.

توجد فروقات بالنسبة للعبارات 1 ، 2 ، 4 ، 5. 5، 6،

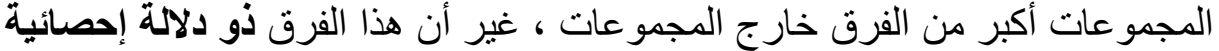

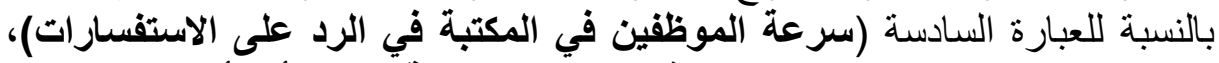

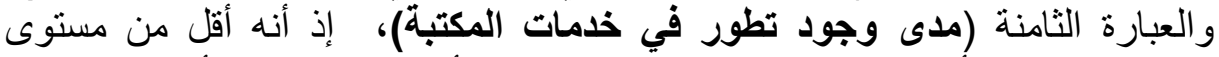
معنوية الدراسة (أقل من 5 \%\%)، بالنسبة للعبار ات الأخرى، فلا توجد أي فروق ذات ذات دلالة إحصائية (العبارة 7 و 3 ) من

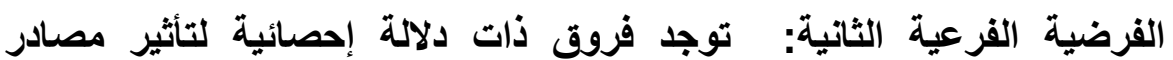
المعلومات باختلاف سنوات الفرعة الدانية:

الجدول رقم (07): تحليل التباين لمصادر المعلومات حسب معيار سنوات

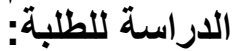

\begin{tabular}{|c|c|c|c|c|c|c|}
\hline الدلالة & $\mathbf{F}$ & المربعات & المجربعات & & البيان & \\
\hline \multirow{2}{*}{0.734} & \multirow{2}{*}{0.427} & 0.452 & 1.55 & المجموعات & \multirow{2}{*}{ والمتياجاتي الورقية متوفرة المراجع } & \\
\hline & & 0.059 & 87.909 & المجموعات & & \\
\hline \multirow{2}{*}{0.281} & \multirow{2}{*}{1.297} & 0.219 & 3.658 & المجموعات & \multirow{2}{*}{ والمتياداتي الإكترونية منتوفرة المراجع } & \\
\hline & & 0.940 & 78.020 & المجموعات & & \\
\hline \multirow{2}{*}{0.272} & \multirow{2}{*}{1.323} & 0.019 & 3.658 & المجموعات & \multirow{2}{*}{ المراجع والمصادر في المكتبة } & \\
\hline & & 0.770 & 63.931 & المجموعات & & \\
\hline 0.797 & 0.339 & 0.509 & 1.526 & المجموعات & أماكنبها والمواد متواجدة دائما في & المعلومات \\
\hline
\end{tabular}




\begin{tabular}{|c|c|c|c|c|c|}
\hline & & 0.499 & 124.405 & المجموعات & \\
\hline \multirow{2}{*}{0.000} & \multirow{2}{*}{7.038} & 0.454 & 22.263 & المجموعات & \multirow{2}{*}{ هناك ت تنوع في المصادر كتب ، إلكترونية ، } \\
\hline & & 0.059 & 87.913 & المحموعات & \\
\hline
\end{tabular}

المصدر : من إعداد فريق البحث على ضوء نتائج الاستبيان.

توجد فروقات بالنسبة للعبار ات 1، 4 ، 5 غير أن الفروقات ذات دلالة إحصائية

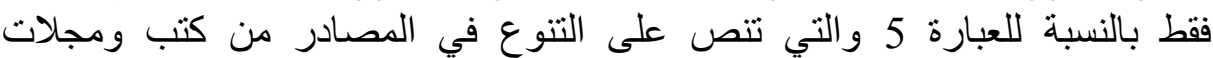
ومكتبات إلكترونية أما عبارة مدى توفر المصادر الإلكترونية ومدى العارئ حداثة المراجع و الكتب (العبارة 2 و العبارة 3 ) فلا نوجد فروقية توفات ذات دلاتلة إحصائية.

الفرضية الفرعية الثالثة: توجد فروق ذات دلالة إحصائية لتأثير الجو العام للمكتبة ، فيما يتعلق بسنواتة الثراتة الاراسة : الجدول رقم (08): تحليل التباين لتأثير الجو العام للمكتبة حسب معيار سنوات الار اسة للطلبة

\begin{tabular}{|c|c|c|c|c|c|c|}
\hline الدلالة & $\mathbf{F}$ & متوسط & المربعوع & \multicolumn{3}{|c|}{ البيان } \\
\hline \multirow{2}{*}{0.072} & \multirow{2}{*}{2.414} & 3.583 & 10.345 & المجموعات & \multirow{2}{*}{ جو المكتبة والهدوء } & \multirow{8}{*}{ للمكتبة } \\
\hline & & 1.484 & 123.206 & المجموعات & & \\
\hline \multirow{2}{*}{0.674} & \multirow{2}{*}{0.513} & 0.664 & 19.06 & المجموعات & \multirow{2}{*}{ المكتبة نظيفة ومرتبة } & \\
\hline & & 1.294 & 107 & المجموعات & & \\
\hline \multirow{2}{*}{0.412} & \multirow{2}{*}{0.968} & 1.236 & 3.160 & المجموعات & \multirow{2}{*}{ التهوية في المكتبة } & \\
\hline & & 1.276 & 105.66 & المجموعات & & \\
\hline \multirow{2}{*}{0.376} & \multirow{2}{*}{1.048} & 1.206 & 3.692 & المجموعات & \multirow{2}{*}{ مقاعد ومناضد } & \\
\hline & & 1.150 & 95.425 & خارجات & & \\
\hline
\end{tabular}

المصدر : من إعداد فريق البحث على ضوء نتائج الاستبيان. 
توجد فروقات بالنسبة للعبارتين الأولى والرابعة وهي ذات دلالة إحصائية بالنسبة

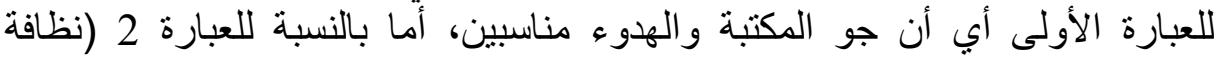
المكتبة) و العبارة 3 (التهوية في المكتبة) فلا توجد فروقات ذات ذات دلالة إحصائية . بشكل عام و على ضوء نتائج تحليل التباين يمكن القول أن الفرضية الثانية غير

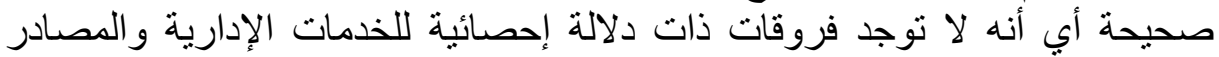

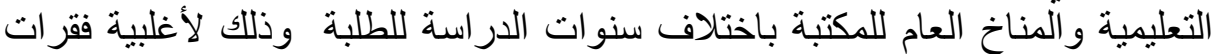

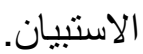

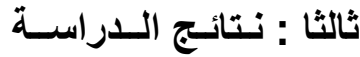

من خلال النتائج المتحصل عليها في هذه الدراسة وجدنا أن مستوى جودة الخدمات

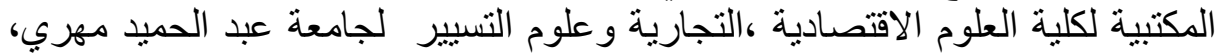

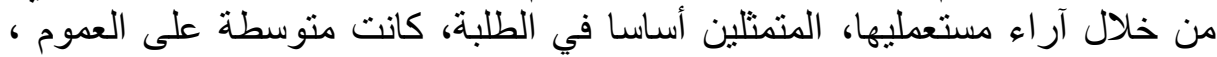

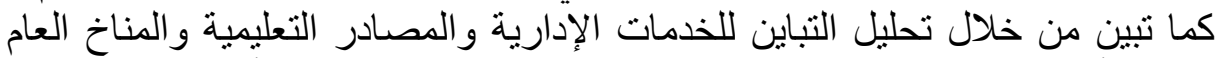

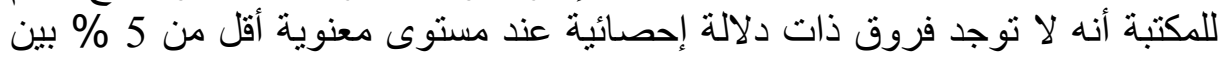

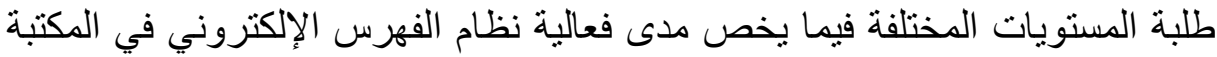

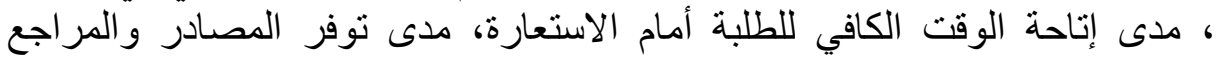

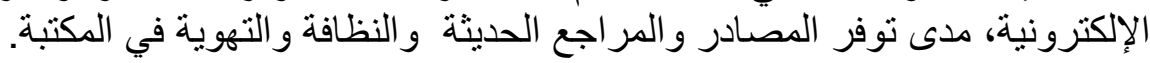

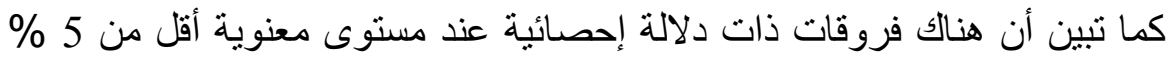

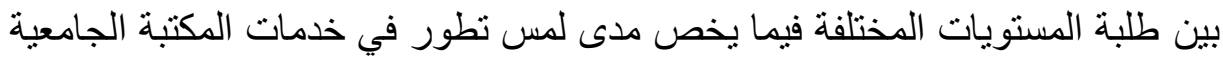

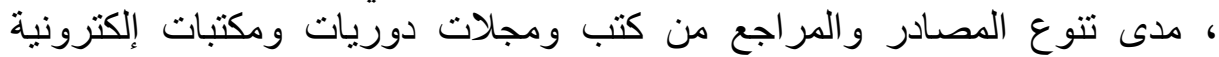
بالإضافة إلى مدى توفر جو هادئ ومناسب للإر اسة في المكتبة .

$$
\text { ويمكن إرجاع هذه النتائج إلى: }
$$

- سلوك موظفي المكتبة وطريقة تصرفهم مع الطلاب تؤثر على استخدام

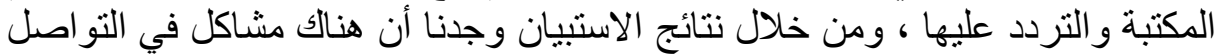

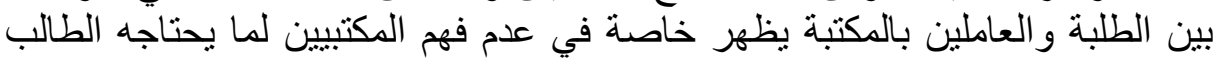
بسر عة ، مما بصعب العملين عملية الاستعارة؛

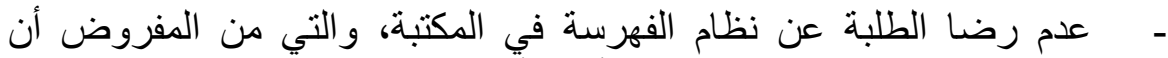
تساعد الطالب على سرعة إيجاد المرجع أو التأكد من عدم وجودهن، حتى لا لا يضيع الوقت في البحث عنه؛

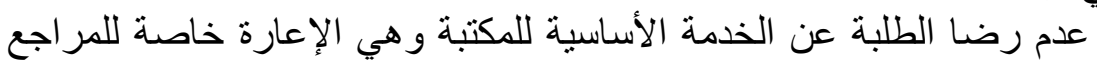

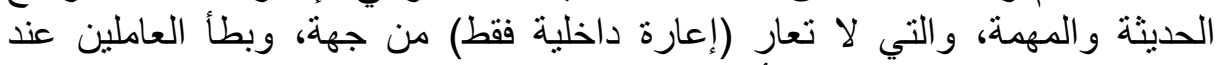
تزويدهم بهذه المر اجع من جهة أخرى؛ لأن إعارة 
- - ل المخصصة لذلك ومشكل الانقطاع المتكرر لخدمة الإنترنت؛

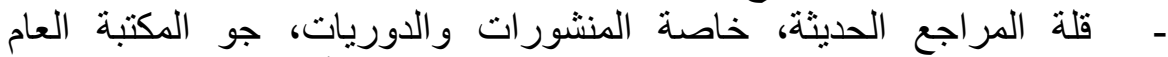

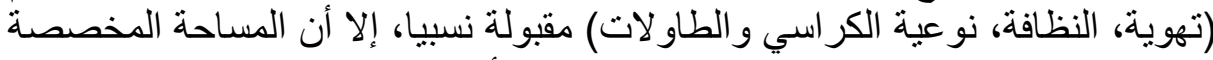

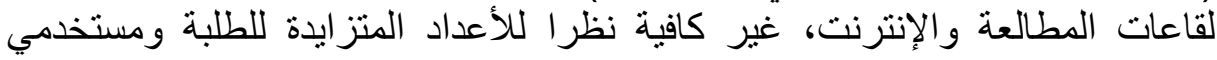

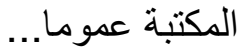

الخاتمة

لكي تفي المكتبة الجامعية لكلية العلوم الاقتصادية،التجارية وعلوم التسيير لجامعة

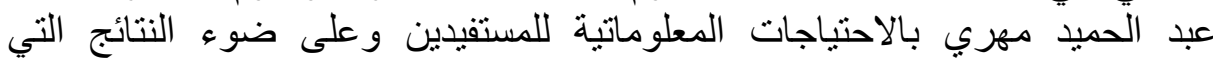

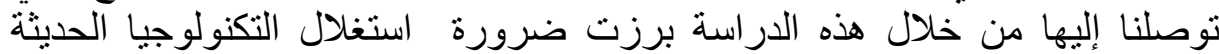

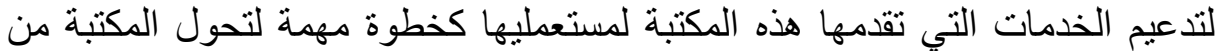

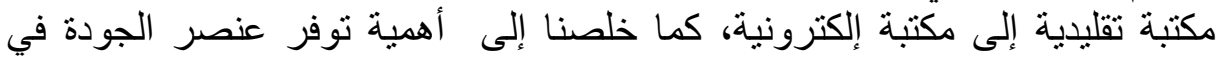

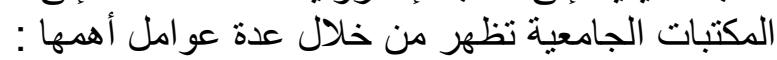
- تحسين نوعية ومستوى الخدمات ؛

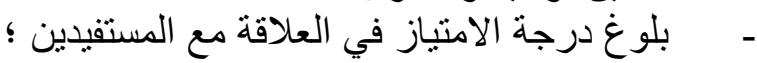

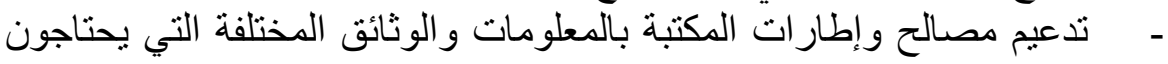

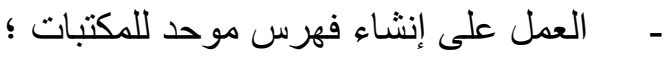

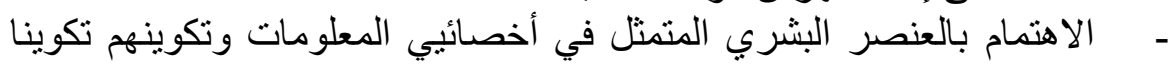

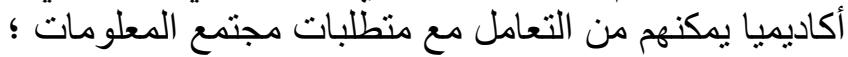

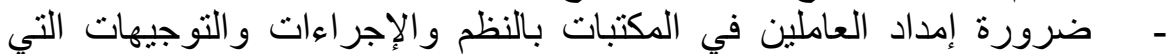
تضمن لهم حسن سير العمل بالكفاءة المطلوبة فئ فئاء

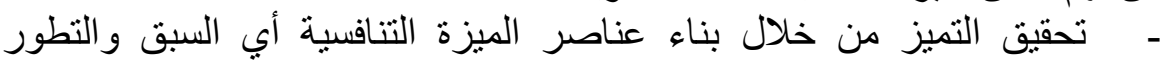

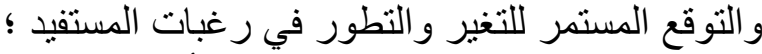
-

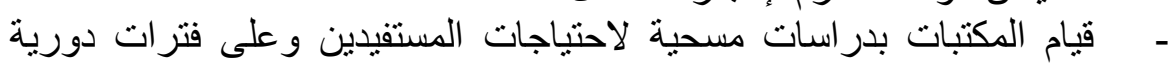

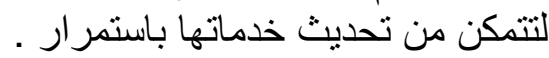

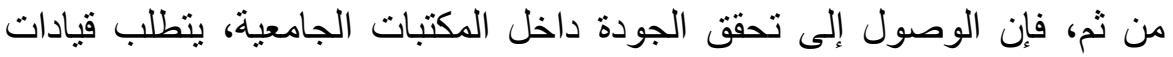

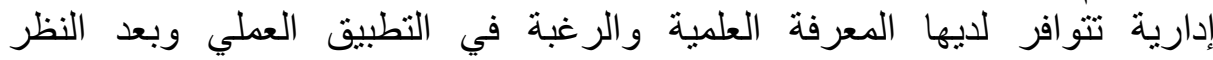
الإستر اتيجي في ترسيخ العلاقة بين العاملين بالمكتبة و المستفيدين من خدماتهين العها.

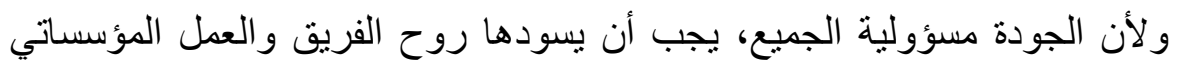

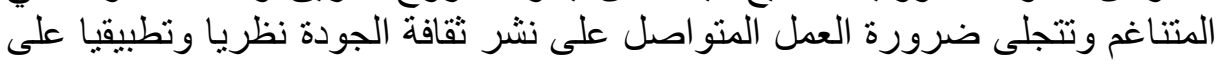

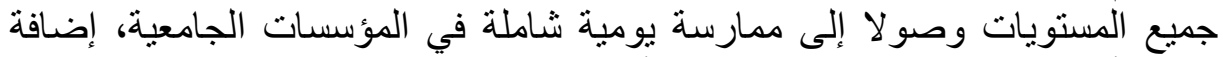
إلى التأكيد على عملية التقويم كجزء أساسي من عملية التحسين المستمر للعملية 


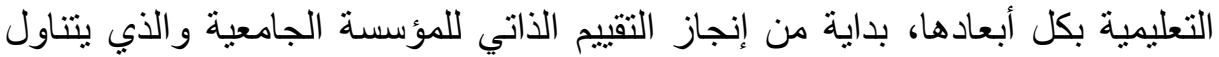

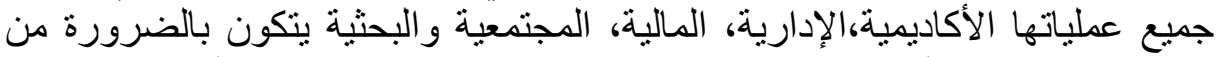

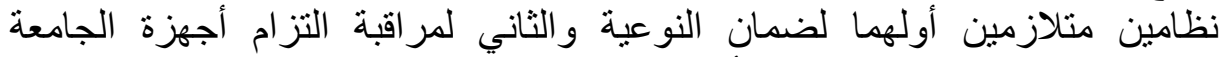

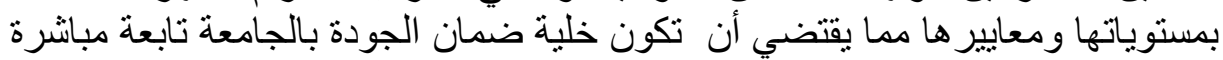

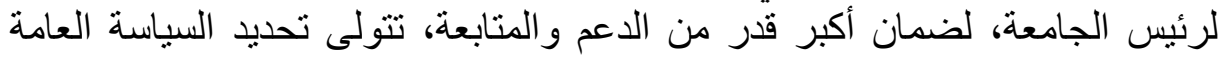

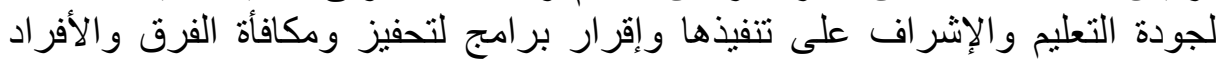

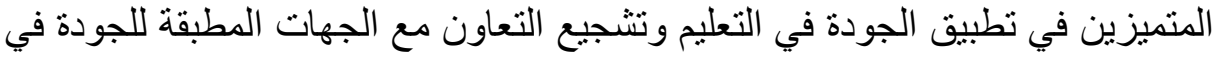
التعليم محليا و عربيا ودوليا.

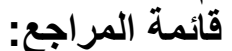

1- Inglis, A, «Holistic Model for quality in higher education: Development , implementation and implication » quality assurance in education, 2011, vol 19, iss 4, pp 451-452.

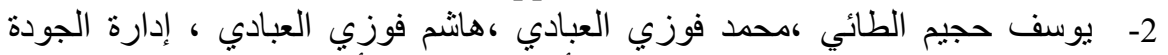

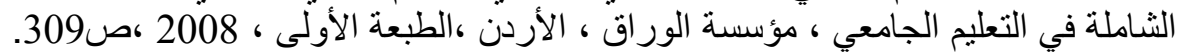

3- quality assurance in higher education, 2014,from: http://www.unesco.org/new/fr/education/themes/strengthening-education-systems/higher-education/quality-assurance.

4- Academic Standards and Qualit; Quality assurance and enhancement ,from : http://www.qaa.ac.uk/

5- Quality procedures on Higher Education, , ENQA Occasional papers 5 , Helsinki , Finland , 2003 ,41 Pages , from:

http://www.enqa.eu/files / procedures.pdf

6- Corner trevor, Abdulai Abukari , 2010 , Delivering higher education to meet local needs in a developing context: the quality dilemmas quality assurance in education, vol 18 iss 3 pp191-208.

7- Dejean ,J «Les démarches qualité dans l'enseignement supérieur en Europe », Paris :Harmattan ,2007, pp 15-53

8- Curaf ,A,\&Scott , P, \&Vlasceanu,L, \& Wilson ,L, « European higher education at the crossroads between the bologna process and national reformes , part 1, 2012,Dordrecht, springer.

9- Khodayar Abili , Fatemeh Narenji, Faranak mokhtarian, mohammad mehdi Rachidi «Assessing quality gap of university services», Asian Journal on quality,(2011),vol 12 iss :2 pp167-175.

10- القيسي هناء محمود ، فلسفة إدارة الجودة في التربية والتعليم العالي الأساليب التاليب

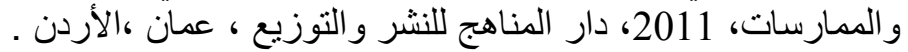

11- Rajani Jain, Gantam Sinha, Sangeeta Sahney, conceptualzing service quality in higher education, Asian Journal on quality , 2011, vol 12 iss 3 pp 296, 314. 


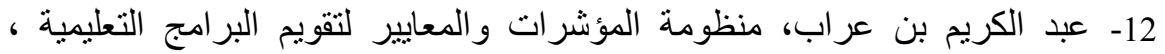

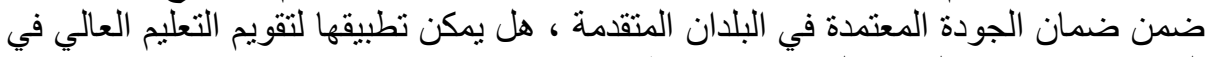
الجز ائر ، 2014 ،ملتقى دولي جامعة قسنطينة 2.

13- Cheng Yin Cheong, Quality assurance in education internal, inference and future, journal of quality in education, vol II no 4 pp 202,243. 14- ر رافدة عمر الحريري ،القيادة و إدارة الجودة في التعليم العالي، دار الثقافة للنشر

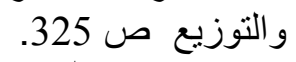

، 15- محمد الهجرسي، المكتبات و المعلومات بالمدارس و الكليات، الطبعة الأولى، القاهرة

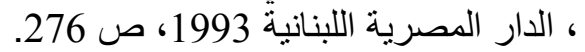

16- Vinocur,A , La qualité de la mesure de la qualité dans l'enseignement supérieur: essai d'analyse économique, journal Education et Société ,2006 n¹8,pp 109-124.

17- محمد الهجرسي، المكتبات و المعلومات بالمدارس و الكليات ، الطبعة الأولى، القاهرة

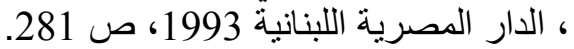

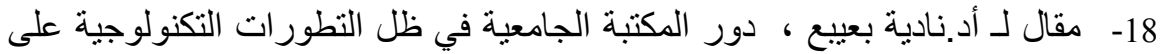

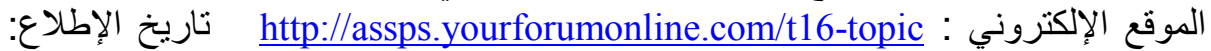

15.30 2013/04/15

19- مقال لـ أد.نادية بعييع ، دور المكتبة الجامعية في ظل التطورات التكنولوجية على التئ

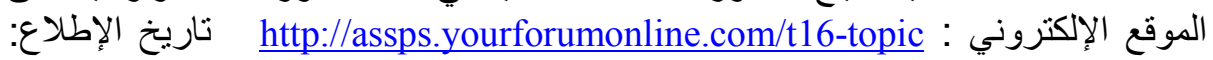

15.30 2013/04/15

20- http://www.univ-constantine2.dz/facsecsg/bibliotheque/def biblio- 